\title{
Govindjee at 80: more than 50 years of free energy for photosynthesis
}

\author{
Julian J. Eaton-Rye
}

Received: 15 August 2013/Accepted: 26 August 2013/Published online: 10 October 2013

(C) Springer Science+Business Media Dordrecht 2013

\begin{abstract}
We provide here a glimpse of Govindjee and his pioneering contributions on the two light reactions and the two pigment systems, particularly on the waterplastoquinone oxido-reductase, Photosystem II. His focus has been on excitation energy transfer; primary photochemistry, and the role of bicarbonate in electron and proton transfer. His major tools have been kinetics and spectroscopy (absorption and fluorescence), and he has provided an understanding of both thermoluminescence and delayed light emission in plants and algae. He pioneered the use of lifetime of fluorescence measurements to study the phenomenon of photoprotection in plants and algae. He, however, is both a generalist and a specialist all at the same time. He communicates very effectively his passion for photosynthesis to the novice as well as professionals. He has been a prolific author, outstanding lecturer and an editor par excellence. He is the founder not only of the Historical Corner of Photosynthesis Research, but of the highly valued Series Advances in Photosynthesis and Respiration Including Bioenergy and Related Processes. He reaches out to young people by distributing Z-scheme posters, presenting Awards of
\end{abstract}

This Tribute to Govindjee was invited and approved for publication by the Guest Editors of the special issues on "Photosynthesis Education", dedicated to Govindjee: Suleyman Allakhverdiev (Russia), Gerry Edwards (USA) and Jian-Ren Shen (Japan).

J. J. Eaton-Rye $(\square)$

Department of Biochemistry, University of Otago, P.O. Box 56,

Dunedin 9054, New Zealand

e-mail: julian.eaton-rye@otago.ac.nz books, and through tri-annual articles on "Photosynthesis Web Resources". At home, at the University of Illinois at Urbana-Champaign, he has established student Awards for Excellence in Biological Sciences. On behalf of all his former graduate students and associates, I wish him a Happy 80th birthday. I have included here several tributes to Govindjee by his well-wishers. These write-ups express the high regard the photosynthesis community holds for "Gov" and illuminate the different facets of his life and associations.

Keywords Bicarbonate, role of - Chlorophyll fluorescence - Delayed light emission - Lifetime of chlorophyll fluorescence - Photosynthesis web resources · Photosystem II · Primary photochemistry · Thermoluminescence · Two light reactions - Two pigment systems · Virus-induced metabolic changes . Z-scheme of photosynthesis
Abbreviations
PS I Photosystem I
PS II Photosystem II
$\mathrm{Q}_{\mathrm{A}} \quad$ Primary plastoquinone electron acceptor of PS II
$\mathrm{Q}_{\mathrm{B}} \quad$ Secondary plastoquinone electron acceptor of PS II 
What follows is a Shloka in Sanskrit for Photosynthesis and Govindjee's 80th birthday

$$
\text { सादरम् सस्नेहम् समर्पणम् | }
$$

ओषध्धः खलु सन्ति जीवनम् सर्वप्राणिनाम् |
पुष्पं पत्रं फलं संपद् अर्पयन्ति सदैव हि $\|$
विश्वसंतुलनकार्यार्थे याः सन्ति नित्यतत्पराः|
नवनवरूपाणि संधृत्य प्राप्तसंकल्पाः भवन्ति ताः ||
सम्यक् विश्लेषणेन ये वर्धयन्ति विश्वज्ञानकोशः|
तेभ्यःवनस्पतिशास्त्रजेभ्यः नतशीर्षाः नमामः ॥
गोविन्दजीसममहोदयेश्यः विश्वज्ञानवर्धकेभ्यः|
शतशतनमस्कारान् सादरम् सस्नेहम् समर्पयामः॥

When translated in English, it means:

"Plants, which consistently offer flowers, leaves and fruit, are indeed the life of all creation. They strive to sustain harmony and balance in the universe and, by eternally adopting ever new forms, they accomplish their goal. With our heads bowed down, we pay our reverence to the botanists [plant biologists], who with their meticulous analysis of the plants, contribute to the knowledge of the universe. We offer to Govindjee, who is one of these scientists, our "hundreds of Namaskara" which is the "hundredfold expression" of our gratitude, love, and respect for him."

\section{Introduction}

I am delighted to have been invited by the guest editors of these special issues on Photosynthesis Education (Suleyman Allakhverdiev, Gerry Edwards and Jian-Ren Shen) to prepare this tribute to Govindjee as we celebrate his 80th birthday (see their Editorial, this issue). I have known Govindjee since the time I became his $\mathrm{PhD}$ student at the University of Illinois at Urbana-Champaign in 1981. Govindjee was an outstanding mentor to all who passed through his laboratory and he continues to provide support and to promote our careers even now many years after we have left his lab. Govindjee's laboratory was always a place of great camaraderie where we were given a great deal of freedom to pursue our research topics but all the while Govindjee steered us in the appropriate direction to begin an independent research and academic career. All who have passed through Govindjee's lab and who have collaborated with him across the years have benefitted enormously from his enthusiasm, passion, encouragement and friendship.
A special message from the Govindjee family

The Govindjee family is extremely pleased to hear about the Photosynthesis Research Special Issue honoring Professor Govindjee's 80th birthday. We like to joke that our father is "Mr. Photosynthesis" since our dinner conversations, teatimes, and even vacations (!) have been full of the news of exciting discoveries and interesting tidbits from the field of photosynthesis. Govindjee is passionate about teaching photosynthesis to all ages_-including his granddaughter who was able to talk about Photosystem II as a toddler! And there isn't a member of his family who doesn't know what the $\mathrm{Z}$ scheme is. It is therefore a fitting tribute for his milestone birthday to honor it with special Educational and Research Issues. We are so glad to see these issues come to fruition and are grateful to all who have made it possible and to all the contributors. As Professor Govindjee would say,

Let There be Light...

Let There be Greenness...

Let There be Water...

Let There be Carbon-di-oxide...

And (by $\mathrm{WAC}^{1}$ )

Let There be Quantum Mechanical Rules

for Electron and Proton Transfer, and, of course, Orderly Membrane Protein Assembly... And, More!

And, you will have Oxygen to breathe with... And, of course, Food to eat!

With Kind Regards,

The Govindjee family

(Submitted by Anita, Govindjee's daughter; see Fig. 1 for pictures of the family.)

Govindjee: Who is he?

For those who don't know Govindjee, I provide here a brief biography. For details, see Eaton-Rye 2007a, b. Govindjee was born on October 24, 1932, at Allahabad, Uttar Pradesh, India, to Mr. Vishveshwar Prasad Asthana and Mrs. Savitri Devi Asthana. However, somehow, official records had listed his date of birth as October 24, 1933. Thus, we are celebrating his 80th birthday in 2013. Further, Govindjee, who uses one name only, did have a family name. In fact, he was Govindji Asthana; not only his last name was dropped, he even changed the spelling of his first name to Govindjee, and, further, it is now used as his last name. Thus, what has happened now is that he is often listed as FNU Govindjee (where FNU stands for First Name Unknown) because computers need all fields filled! Since he uses one name only

\footnotetext{
1 The part "Let There be Quantum..... And More!" was added by Govindjee at the suggestion of William A. Cramer (WAC), Professor of Biological Sciences, Purdue University.
} 
Fig. 12013 photographs of Govindjee and his family. Top Left: A photograph of

Govindjee with his wife Rajni; Top Right: Govindjee (in the middle) with his daughter Anita Govindjee, and his son Sanjay Govindjee (http://www.ce. berkeley.edu/ sanjay/). Bottom: Left to right: Sanjay, Rajni, Marilyn Govindjee, Govindjee, Sunita Christiansen, Rajiv Govindjee, Arjun Govindjee, Anita Govindjee-Christiansen, and Morten Christiansen (http:// psych.cornell.edu/people/ morten-christiansen). Sunita is Anita and Morten's daughter; and Arjun and Rajiv are Sanjay and Marilyn's sons
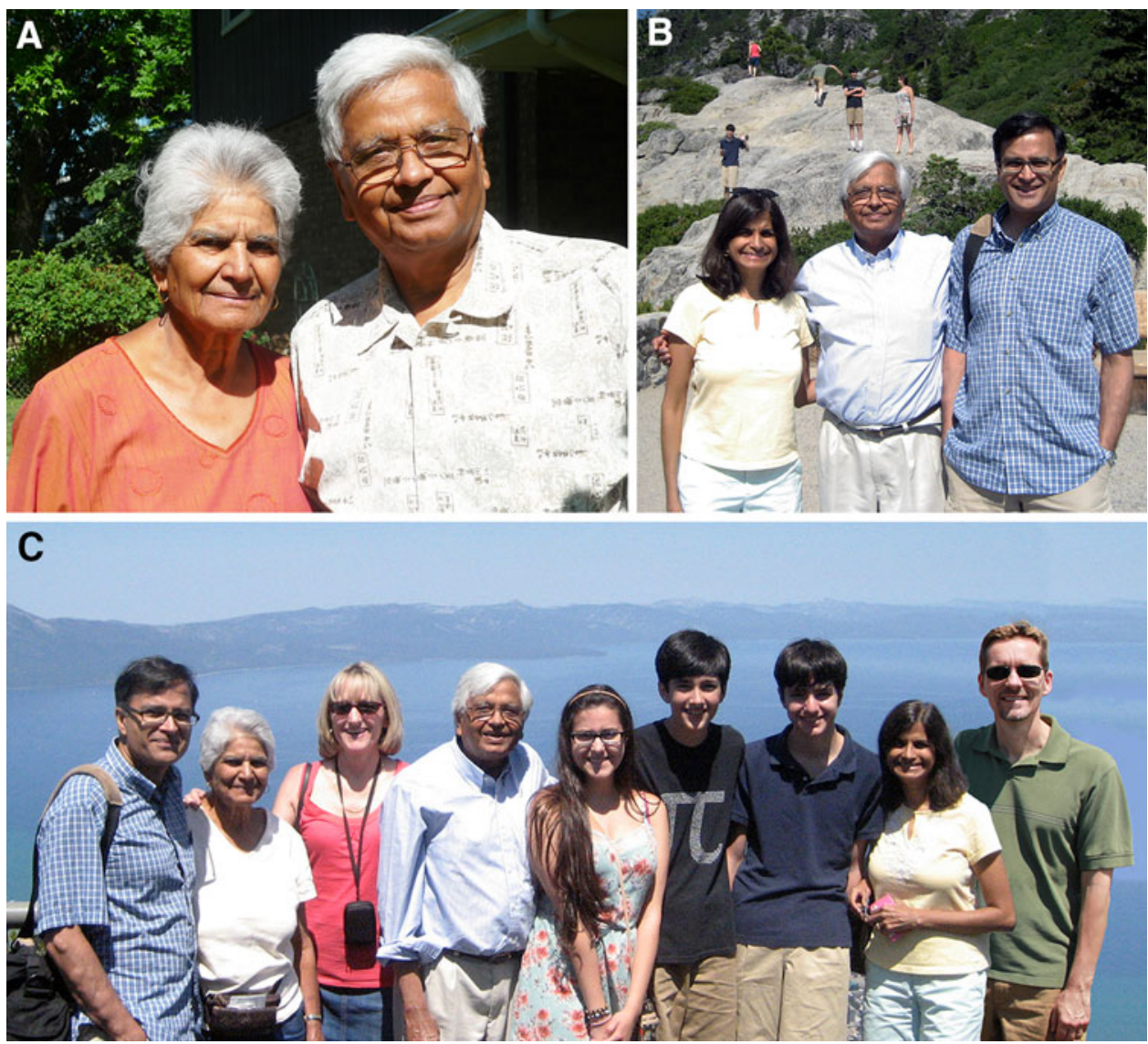

and computers need 2 names, he has been listed by various names including: Mister Govindjee, Illini Govindjee, and Govindjee Govindjee. His family has no problem: his wife is Rajni Govindjee (retired senior biophysicist from the University of Illinois at Urbana-Champaign); his daughter is Anita Govindjee (working for IBM; her husband Morten Christiansen is Professor of Psychology at Cornell University); and his son is Sanjay Govindjee (Professor at University of California Berkeley; his wife Marilyn Govindjee teaches Spanish in California). Govindjee has 3 grandchildren (Sunita Christiansen; Arjun Govindjee; and Rajiv Govindjee). Figure 1 shows a 2013 photograph of Govindjee and his immediate family during a 2013 family reunion in the Lake Tahoe area in California. I would like to mention that he has an elder sister Malati Sahay (retired professor of Hindi, who lives in India), and an older brother Gopalji (retired chief executive of an Engineering enterprise of the Government of India, who also lives in India). His eldest brother Krishnaji (1922-1997), who was a professor of Physics at the University of Allahabad, was his mentor and responsible for shaping his life. For a wonderful Tribute to Professor Krishnaji, see Govindjee and Srivastava (2010).

Govindjee received his BSc in 1952 in Chemistry, Botany and Zoology, and his MSc in 1954 in Botany (specializing in Plant Physiology), both from the University of Allahabad.
He obtained his $\mathrm{PhD}$ in Biophysics in 1960 from the University of Illinois at Urbana-Champaign, where he studied under two pioneers: Robert Emerson (Sep. 1956-Feb. 1959) and Eugene Rabinowitch (March 1959-Sep. 1960). He has held the following positions: 1960-1961: United States Public Health Service Postdoctoral Fellow; 1961-1965: Assistant Professor of Botany; 1965-1969: Associate Professor of Botany and of Biophysics; 1969-1999: Professor of Biophysics and Plant Biology; 1999-present: Professor Emeritus of Biochemistry, Biophysics and Plant Biology. His collaborative spirit, his teaching spirit and other activities are described in Eaton-Rye (2007a). I recommend the readers to see a large collection of photographs of Govindjee's younger days as well as photographs of most of his $\mathrm{PhD}$ students and his postdoctoral associates in Eaton-Rye (2007b). In addition, Eaton-Rye (2007b) has a list of PhD theses of all his students as well as names of his 303 collaborators. Since then, this number has risen to at least 350 (see Appendix 1). It shows how he is constantly interacting with many around the World. I suspect this keeps him young.

Not surprisingly, beyond his ongoing research and educational activities, Govindjee enjoys recognizing students at conferences by giving them book awards (see e.g., Moore et al. 2012), and/or congratulating those who receive the Govindjee and Rajni Govindjee Awards for 
Excellence in Biological Sciences (see e.g., Fig. 2 for pictures of the 2013 Awardees). An example of his recognition of his past students is his writing recollections of one of his distinguished students Tom Wydrzynski (see Govindjee 2008).

What follows deals with some selected highlights of his research. This text is divided into the following sections, and, then, we present at the end Tributes from friends and colleagues around the World.

Pre-Photosynthesis Days (1955): Govindjee's early fascination with paper chromatography and virus infection: first paper published in Nature

Major discoveries and contributions of Govindjee in understanding molecular mechanisms of Photosynthesis. It is divided into seven sections:
1. On the two light reaction and two-pigment system in oxygenic photosynthesis: beyond Robert Emerson

2. How does the minimum quantum requirement for oxygen evolution fit the above picture? And, what did Govindjee do?

3. On the discovery of new absorption and emission bands in photosynthesis: brief comments

4. Understanding of the mechanism of thermoluminescence and delayed light emission in photosynthetic systems: beyond William Arnold

5. On the very first measurement of primary charge separation in Photosystem II

6. The unique role of bicarbonate (hydrogen carbonate) in Photosystem II: beyond Otto Warburg

7. What Govindjee loves the most is: chlorophyll $a$ fluorescence and its relationship to photosynthesis; he was
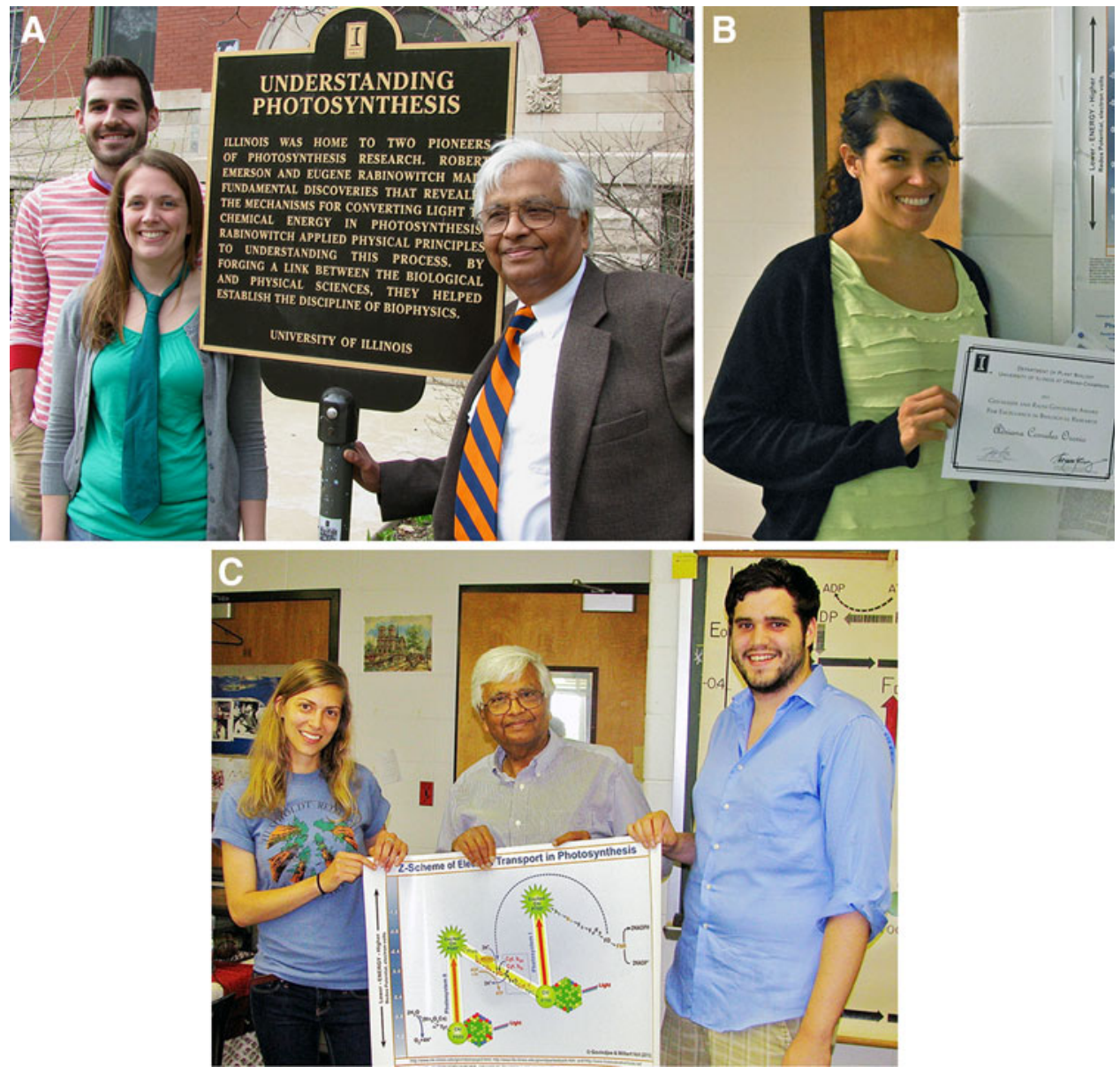

Fig. 2 Photographs of five 2013 Govindjee and Rajni Govindjee Awardees for Excellence in Biological Science. Top Left: Left to right: Robert Koester, Rebecca Slattery; the plaque for Eugene Rabinowitch \& Robert Emerson; and Govindjee. Top Right: Adriana Corrales Osorio showing her Award certificate; Bottom: Left to right: Samantha B. Primer and Robert Van Buren holding the current Z-Scheme of photosynthesis; and Govindjee; in the background is the $1965 \mathrm{Z}$-Scheme of Govindjee. [We note that the Z-scheme designed by him and Wilbert Veit is being distributed by the two free around the World for education purposes. See Fig. 4 in Orr and Govindjee (2013); also see http://www.life.illinois.edu/govindjee/photoweb/ subjects.html\#Light-reactions. Photographs of the 2012 and earlier Govindjee and Rajni Govindjee Awardees for Excellence in Biological Science are at (or linked from it): http://www.life.illinois.edu/ govindjee/photooftheyear2012.html 
the first one to introduce measurements of lifetime of chlorophyll $a$ fluorescence to understand photoprotection in plants.

\section{Pre-photosynthesis days (1955): Govindjee's early fascination with paper chromatography and virus infection: first paper published in Nature}

Govindjee has been contributing original research articles on photosynthesis since 1960, yet his scientific publishing career actually began while he was a lecturer in Botany at the University of Allahabad in 1955; remarkably, in 2 years he will celebrate 60 years of research. Having topped his MSc Botany class (first class, first position), in 1954, at Allahabad University, Govindjee was immediately hired by Shri Ranjan, Head of the Department of Botany, as a Lecturer to teach Plant Physiology to the following class of MSc students. Already at this early stage in his career Govindjee had become interested in photosynthesis after he had run a mock symposium (where students represented such pioneers as Joseph Priestly, Jan Ingen-Housz, Johann Baptista van Helmont, Otto H. Warburg and Robert Emerson amongst others) but there were no facilities to do research in photosynthesis in the Department at that time. He, however, quickly, although only for a short while, became fascinated with another topic: what virus infection does to the metabolism of plants; this interest stemmed from when he had watched yellowed and sickly plants, growing in his uncle's garden, and wondered about them. Working on this project in Ranjan's laboratory, he published his first paper (Laloraya and Govindjee 1955) in Nature. Laloraya, the first author of this paper, had been a classmate of his since school days, and was at the time a PhD student of Ranjan. In this paper, the two discovered that tobacco-mosaic virus and tobacco-leaf curl virus had caused an increase in asparagine and several amino acids, especially aspartic acid, supporting the idea that virus infection may cause the formation of new proteins in the infected plants (for one of the earliest books on plant viruses, see Bawden (1943)), and that it leads to changes in free amino acids (Commoner and Nehari 1953). The work on tobacco had, however, been concurrent with the work on the diseased leaves of Croton sparsiflorus by Govindjee and Laloraya (Ranjan et al. 1955); here, a detailed method of using a 16-sector radial-cut circular filter paper horizontal chromatography was described for the first time; the idea of radial cuts was initially suggested by another $\mathrm{PhD}$ student of Ranjan, T. Rajarao, but it was perfected in Ranjan et al. (1955); also see Laloraya et al. (1955). Yellow-mosaicinfected leaves of Croton had contained more of free lysine and histidine than the healthy leaves, again supporting Bawden's and Commoner's views. Conclusions of this research were soon tested, on many virus-infected plants by this group, working almost day and night, I am told, on Trichosanthes anguina (Rajarao et al. 1956), on Carica sp. (Laloraya et al. 1956), and on Abelmoschus esculentus (Govindjee et al. 1956). (We note that Rajni Varma had joined the "team" of Govindjee, Laloraya and Rajarao, all working under Shri Ranjan; see a photograph at the very bottom of the web page at http://www.life.illinois.edu/ govindjee/; 2 years later Rajni Varma married Govindjee, while she was also a student of Robert Emerson, and the rest, as they say, is history.) This area was soon followed by research in Israel on virus-infected maize plants (Harpaz and Appelbaum 1961), and then by Magyarosy et al. (1973) on squash (Cucurbita maxima) in the USA, among others.

An interesting story on the day of the success by $\mathrm{M}$. M. Laloraya and Govindjee in paper chromatographic separation of free amino acids in many samples that involves Shri Ranjan, supervisor of Govindjee, and of Laloraya, is available at http://www.life.illinois.edu/ govindjee/ranjan.html. What is not said there is why and how Ranjan's name was not on the Nature paper. First of all, it seems that Govindjee and Laloraya may have been naive about how the system works; it seems from many publications during that time that Ranjan was not interested in having his name on their papers on this topic. However, as Govindjee recalls: after the Nature paper was accepted, he and Laloraya went to Ranjan's office to tell him the great news. It was then that Ranjan informed the two that they must send all their future papers through his office! Had they understood the importance of this issue, I am sure they would have included Shri Ranjan in the paper as he was their great mentor. This was perhaps a formative moment in Govindjee's career as anyone who has worked with Govindjee knows, he always ensures that all contributors are included as authors on manuscripts.

\section{Major discoveries and contributions of Govindjee in understanding molecular mechanisms of Photosynthesis}

Govindjee is an authority, and a pioneer of the "Light Reactions of Plant and Algal Photosynthesis", particularly of Photosystem II (PS II), the system that oxidizes water to oxygen, and reduces plastoquinone to plastoquinol. He has coauthored more than 400 research papers and major reviews in many peer-reviewed journals including Science, Proceedings of the National Academy of Science USA, Plant Physiology, Biophysical Journal, Photochemistry and Photobiology, Biochimica et Biophysica Acta, and Photosynthesis Research. His major contributions have been on the mechanism of excitation energy transfer, on light emission (prompt and delayed fluorescence; and thermoluminescence), on primary photochemistry, and on 
electron transfer in PS II. He has had the drive, the motivation, and ingenuity in solving problems not only through "action", but through collaboration with those who complemented his biological and biophysical background, especially those with training in chemistry and in physics. Govindjee's many contributions have been summarized in Papageorgiou (2012a), Eaton-Rye (2012) and Clegg (2012), and his publications are also on his web page at:

http://www.life.illinois.edu/govindjee/pubschron.html; and http://www.life.illinois.edu/govindjee/recent_papers. html.

Below, the seven topics that have been selected to illustrate the breadth of Govindjee's research output over the years are presented.

1. On the two light reaction and two-pigment system in oxygenic photosynthesis: beyond Robert Emerson

When Robert Emerson discovered, in 1957, the "enhancement effect" in photosynthesis-where two beams of different wavelengths of light, given simultaneously, gave higher rates of photosynthesis, than the sum of the rates in the two beams given separately (Emerson et al. 1957; Emerson and Chalmers 1958), it led to the concept of two light reactions and two pigment systems. There were, however, two serious issues with Emerson's work: (1) the conclusion that one system was run by chlorophyll $a$ and the other by chlorophyll $b$ was untenable since Duysens (1952) had shown that $100 \%$ of energy absorbed by chlorophyll $b$ was transferred to chlorophyll $a$, and (2) since Emerson had used manometry, one could not be sure if the effect was on photosynthesis or respiration. The dilemma in the first issue was solved in Govindjee's PhD thesis (1960, under Eugene Rabinowitch). It is this work that established that both the photosystems were run by chlorophyll $a$ : a shortwave form of chlorophyll $a$ was in the same system that had chlorophyll $b$ (Govindjee and Rabinowitch 1960). Further, Govindjee et al. (1960a) discovered a two-light effect in chlorophyll $a$ fluorescence, and Rajni Govindjee et al. (1960b) solved the dilemma of the second issue when she discovered the Emerson Enhancement Effect in the Hill reaction in Chlorella cells, with an externally added quinone (that had inactivated respiration). However, the final proof came when the Govindjees published their results showing the Emerson Enhancement in NADP (nicotinamide adenine dinucleotide phosphate) reduction in spinach thylakoids (see e.g., Rajni Govindjee et al. 1964). In addition, mass spectroscopic results with Oxygen-18 water provided additional proof that the two-light effect was in photosynthesis, not in respiration (see e.g., Govindjee et al. 1963; also see Owens and Hoch 1963); and the Enhancement Effect was shown to exist even in deuterated Chlorella cells (Bedell and Govindjee 1966). Also throughout this period, Govindjee did extensive work in characterizing the two light reactions and two pigment systems by other biophysical techniques. We do not discuss these results here, but refer to a chapter in a book that discusses the evolution of the current $\mathrm{Z}$-scheme of photosynthesis (see Govindjee and Björn 2012).

2. How does the minimum quantum requirement for oxygen evolution fit the above picture? And, what did Govindjee do?

It is obvious that one would need a minimum of $8-10$ quanta of light to release one molecule of oxygen in the current Z-scheme. Otto Warburg had insisted that this number is $3-4$, not $8-10$, the number that Emerson-who had been Warburg's student-had always favored. Govindjee initially began his $\mathrm{PhD}$ under the supervision of Robert Emerson and held Emerson in high regard. Thus after Emerson's death in 1959, when Warburg started telling people that Emerson's values were wrong because Emerson had not used young synchronous cultures of algae and had not given his Chlorella cells $10 \% \mathrm{CO}_{2}$ that is needed for the low quantum requirement; he, along with Rajni Govindjee, rose to the occasion and repeated the experiments under Warburg's new conditions, and proved Emerson right and Warburg wrong (R. Govindjee et al. 1968). A first discussion was given by Govindjee (1999) and now, the entire controversy is covered in a wonderful book by Nickelsen and Govindjee (2011).

3. On the discovery of new absorption and emission bands in photosynthesis: brief comments

During his studies in the 1960s, and in search of characterizing the pigment systems, Govindjee and coworkers discovered many new absorption and emission bands. Amongst these many reports, several stand out and these give a sense of his curiosity. First was a discovery of a pigment that absorbs at $750 \mathrm{~nm}$, called P750, in the cyanobacterium Anacystis nidulans (now Synechococcus elongatus strain PCC 7942) (Govindjee et al. 1961): it was rediscovered by many and a full story is summarized in Govindjee and Shevela (2011); it is, unfortunately, not involved in photosynthesis. Second, was the independent discovery, in 1963, of a fluorescence band at $696 \mathrm{~nm}(\mathrm{~F} 696)$ at $77 \mathrm{~K}$, this was later proved to arise from the PS II core antenna protein CP47 (its history is also discussed by Govindjee and Shevela (2011)); and lastly, he discovered an emission band in the $693 \mathrm{~nm}-700 \mathrm{~nm}$ range when photosynthesis is saturated at high light, or inhibited by the addition of DCMU (3-(3,4dichlorophenyl)-1,1-dimethylurea); this is the counterpart of the 77 K F696 at room temperature, but was unraveled by taking difference emission spectra (see e.g., Krey and Govindjee 1964; Govindjee and Briantais 1972). Further, 
due to the closure of PS II under these conditions, Govindjee and Briantais were also able to see chlorophyll $b$ fluorescence due to reduced energy transfer from it to chlorophyll $a$ ! When discussing this last point Govindjee was keen to point out that this has not been exploited in current studies and deserves to be pursued for kinetic changes in photosynthesis.

\section{Understanding of the mechanism}

of thermoluminescence and delayed light emission in photosynthetic systems: beyond William Arnold

Govindjee is known for his insight into the mechanism of delayed light emission (or delayed fluorescence) and thermoluminescence. William Arnold, a former student of Robert Emerson, had not only discovered, in 1932, the concept of the "Photosynthetic Unit" with Emerson, but, in 1951, with Bernard Strehler, he discovered delayed light emission, while investigating the possible synthesis of ATP by plants (Strehler and Arnold 1951), and later, in 1957, he discovered the phenomenon of thermoluminescence (afterglow) with Helen Sherwood (Arnold and Sherwood 1957). Mar and Govindjee (1971) discovered that preilluminated spinach chloroplasts and Chlorella pyrenoidosa, when given a quick temperature jump of about $15^{\circ} \mathrm{C}$, emitted light. This thermoluminescence was present both in normal and DCMU-treated samples, where electron transport to PS I was blocked, but was absent when hydroxylamine, which blocks electron transport on the donor side of PS II, was added to these samples. These results were explained not in terms of Arnold's theory of electron-hole reactions, but in terms of a back reaction of PS II of photosynthesis. This, it seems, was the beginning of Govindjee's thoughts on thermoluminescence and his recognition that Arnold's theory was in need of revision. Certainly Govindjee returned to this question when, almost 10 years later, he went to BARC (Bhabha Atomic Research Centre) in Trombay, Bombay (now Mumbai), India, to study thermoluminescence, discovering with V.G. Tatake, P.V. (Raj) Sane and coworkers abnormally large activation energies, using the well-known Randall-Wilkins theory (Tatake et al. 1981). This was an untenable situation, and it led him to approach Don DeVault (co-discoverer, with Britton Chance, of electron tunneling), who was also at Urbana, Illinois, to help him write the equations and theory, using the detailed scheme of PS II reactions that Govindjee presented to him. By postulating temperaturedependent equilibria between two or more electron carriers in PS II, acting as traps for electrons or holes, they modified and extended the existing theories and explained not only the abnormally large activation energies but the abnormal frequency factors involved. It was in this paper that the correct theory of thermoluminescence from plants and algae was born (DeVault et al. 1983) and extended by DeVault and Govindjee (1990). Also see Rutherford et al. (1984) and Rose et al. (2008) for further information on his use of thermoluminescence in understanding PS II.

Further, understanding of delayed light emission (or delayed fluorescence) had consumed Govindjee's curiosity for many years. In 1971, he, with his student Ted Mar, and in collaboration with a group in Physics (William Stacy and Charles Swenberg), proposed (Stacy et al. 1971) an alternate hypothesis for delayed light in the green alga Chlorella: it involved triplet-triplet fusion, instead of the electron-hole recombination theory of William Arnold. Although they could not detect the expected magnetic field effect on the emitted light, the triplet theory was declared to be a valid option based on analysis of all their experimental data. Neither the electron-hole recombination theory, nor the triplet fusion theory has survived. Even before this paper was published, Govindjee had begun work with another student Paul Jursinic - who assembled a new instrument in his Lab. The idea that delayed light emission was due to a back reaction of PS II was explored by using various experimental systems: (1) when electron transport on the electron acceptor side of PS II was blocked by DCMU (Jursinic and Govindjee 1972); (2) when electrons from PS II were diverted to silicomolybdate from $Q_{\mathrm{A}}^{-}$ (Zilinskas and Govindjee 1975); and (3) when electron donation on the water side of PS II was blocked by Triswashing (Jursinic and Govindjee 1977a). All these results were consistent with the back reaction concept. Further, Jursinic and Govindjee (1977b) measured the temperature dependence of delayed light in a few microseconds and hundreds of microseconds and discovered that the former was independent of temperature in the 0 to $35^{\circ} \mathrm{C}$ range, whereas the latter was not. Further, the short-term component had $I^{2}$ dependence, whereas the latter was linear with light intensity. Soon thereafter, and in collaboration with Colin Wraight, also at the University of Illinois, Jursinic and Govindjee discovered that there was a major difference in the microsecond and the millisecond delayed light, the former was insensitive to membrane potential, whereas the latter was sensitive to it in the presence of $\Delta \mathrm{pH}$ (Jursinic et al. 1978). Thus, although most delayed light is due to a back reaction of PS II, detailed mechanisms are different for the fast and slower components. We refer the readers to reviews by Lavorel (1975) and by Govindjee and Jursinic (1979) that cover the literature and the ideas during that period.

5. On the very first measurement of primary charge separation in Photosystem II

Govindjee's heart has always been in PS II and his enthusiasm for research on PS II is infectious. Over 
40 years ago he initiated studies on the mechanism of excitation energy transfer as a function of temperature down to liquid helium temperature (see e.g., Cho and Govindjee 1970a, b), and in the 1970s and 1980s he was also thinking about the various models for oxygen evolution (Mar and Govindjee 1972; Kambara and Govindjee 1985; also see a recent review by Najafpour et al. 2012); during this period he also applied, for the first time, Nuclear Magnetic Resonance (NMR) methods to monitor the oxygen clock (Wydrzynski et al. 1976; Baianu et al. 1984). His drive to find out the nature of the very first intermediates involved and the efficiency and the speed of the primary charge separation led him to approach Mike Wasielewski at Argonne National Lab, and this led to the first successful paper showing that the charge separation occurred from a chlorophyll to a pheophytin molecule, within a few picoseconds (Wasielewski et al. 1989; also see Greenfield et al. 1997). His work on the primary charge separation in PS II with Mike Wasielewski depended heavily on Mike Seibert as he knew how to make stable PS II reaction centers; this collaboration lasted almost 8 years (1989-1997). (See the historical account by Govindjee and Seibert (2010) and the tribute from M. Seibert below.) Govindjee's pioneering measurements including those on PS I primary photochemistry (Fenton et al. 1979; Wasielewski et al. 1987) have stood the test of the time although refinements have been done and a clearer detailed picture is now available.

6. The unique role of bicarbonate (hydrogen carbonate) in Photosystem II: beyond Otto Warburg

Govindjee has always been enamored by things which are different and new and challenge the existing dogma. He is an extraordinary teacher and is a "fire-ball" at times. As Papageorgiou (2012b) put it, he is "like an impatient race car at the starting line". He gave a lecture in his "Bioenergetics of Photosynthesis" course about Otto Warburg's idea that oxygen came from $\mathrm{CO}_{2}$ because Warburg had found that without $\mathrm{CO}_{2}$, thylakoids evolved oxygen at a very reduced rate. This lecture inspired his then graduate student Alan Stemler to take this problem for his $\mathrm{PhD}$ thesis; Alan made remarkable discoveries (PhD, 1975; see e.g., Stemler et al. 1974 for bicarbonate effects on relaxation of the "S-states" of the oxygen-evolving complex), and continues to do so. With another of his PhD students, Thomas Wydrzynski (PhD, 1977), Govindjee discovered that bicarbonate clearly functioned on the electron acceptor side of PS II (Wydrzynski and Govindjee 1975). He then went to the famous lab of Lou Duysens, in Leiden, and discovered a remarkable effect of bicarbonate on the twoelectron gate of PS II (Govindjee et al. 1976; also see Eaton-Rye and Govindjee 1988a, b). The most remarkable and unique discovery in Govindjee's lab has been the establishment of the extraordinary role of bicarbonate (hydrogen carbonate) on the electron acceptor side of PS II, particularly on the protonation events involving the secondary plastoquinone acceptor $Q_{\mathrm{B}}$ binding region. These key studies were done working with several of his graduate students (Paul Jursinic, PhD, 1977; Rita Khanna, PhD, 1980; Wim Vermaas, PhD, 1984 (co-supervised with Prof Jack van Rensen, Wageningen Agricultural University); Danny Blubaugh, PhD, 1987; Julian Eaton Rye (the author), PhD, 1987; Jiancheng Cao, PhD, 1992; Chunhe $\mathrm{Xu}, \mathrm{PhD}, 1992$, and Jin Xiong, PhD, 1996), as well as many research collaborators (Jack van Rensen, among them). (See a review by Shevela et al. (2012) for a complete picture.) Govindjee is great in recognizing and respecting his students; he wants to be sure that the rest of the World can find the PhD theses of his students, who he believes are the ones responsible for what was discovered in his laboratory (see the following web site where all the $22 \mathrm{PhD}$ theses (over a period of 30 years of guidance) are available: <http://www.life.illinois.edu/govindjee/theses. html>).

His special love for the role of bicarbonate in PS II is evident when we see his eyes pop up, like a child, with any mention of "bicarbonate", whether it is a Gordon Conference, or an International Congress. And, he cannot resist asking questions. The 1.9 Angstrom atomic level structure of PS II by Umena et al. (2011) clearly has bicarbonate bound to the non-heme iron between the primary plastoquinone electron acceptor $Q_{\mathrm{A}}$ and the secondary plastoquinone electron acceptor $Q_{\mathrm{B}}$ of PS IIwhere his experiments wanted it to be present. Govindjee, I am sure, is holding his breath for the final molecular mechanism of the role of bicarbonate in bringing protons to the reduced $Q_{\mathrm{B}}$; we now know the amino acids around the site, and it is only a matter of time before the molecular mechanism of the function of this bicarbonate ion will be solved. He has told me many times that he is equally interested in knowing about how bicarbonate functions on the electron donor side of PS II, but he has preferred to leave that problem to other experts working in that area; this includes: Alan Stemler; Slava Klimov, Suleyman Allakhverdiev, Dima Shevela, Johannes Messinger, Chuck Dismukes, among many others. It seems that this donor side bicarbonate may be weakly bound and may be somehow involved in de-protonation/protonation events. We wait for the results.

Let us all hope that by the time Govindjee turns 85 , the labs working on this bicarbonate project will have the answers for him to enjoy the rest of his life! It is my belief that if Govindjee was not 80 , he would be running around to the labs of others insisting on doing the experiments himself! 
7. What Govindjee loves the most is: chlorophyll $a$ fluorescence and its relationship to photosynthesis; he was the first one to introduce measurements of lifetime of chlorophyll $a$ fluorescence to understand photoprotection in plants

Govindjee's main love in the field of photosynthesis has been to relate chlorophyll $a$ fluorescence to photosynthesis, especially to regulation of photosynthesis. This has led to a large number of edited volumes and reviews including: Govindjee et al. (1986), Govindjee (1995, 2004), Strasser et al. (1995), Papageorgiou and Govindjee (2004), Papageorgiou and Govindjee (2011), Stirbet and Govindjee (2011, 2012) and Kalaji et al. (2012). Likewise this area of research has included a large number of graduate students including Carl Cederstrand (PhD, 1965), Louisa Yang (MS, 1965), Anne Krey (MS, 1966), George Papageorgiou (PhD, 1968), John C. Munday (PhD, 1968), Fred Cho (PhD, 1969), Ted Mar (PhD, 1971), Maarib Bazzaz (PhD, 1972), Prasanna Mohanty (PhD, 1972), Paul Jursinic (PhD, 1977), David VanderMeulen (PhD, 1977), Daniel Wong (PhD, 1979), and Paul Spilotro (MS, 1999). In fact Govindjee's name is synonymous with the field of chlorophyll $a$ florescence, in all aspects, but I have decided not to expand here although interested readers should consult the extensive reviews listed above. Instead we will single out fluorescence lifetime measurements below.

Steve Brody, who was at the University of Illinois, before Govindjee went there, was the first to measure lifetime of chlorophyll $a$ fluorescence in a photosynthetic system (see a historical review by Brody (2002)). However, Govindjee pioneered, with Henri Merkelo, use of modelocked lasers to make such measurements (Merkelo et al. 1969), and then subsequently made lifetime of chlorophyll $a$ fluorescence measurements, using the phase method, in Enrico Gratton's group (see e.g., Govindjee et al. 1990).

Govindjee's work, using lifetime measurements of chlorophyll $a$ fluorescence was the first of its kind in understanding photoprotection by plants, under excess light, in terms of changes in rate constants of deactivation of the excited states of chlorophyll since fluorescence intensity changes alone do not distinguish between changes in chlorophyll concentration and changes in rate constants of de-excitation of excited states. The pioneering paper was that by Gilmore et al. (1995), where a dimmer switch was discovered: as more and more light was given to a photosynthetic system, a proportion of chlorophyll $a$ that had a $\sim 2$ ns lifetime of chlorophyll fluorescence was converted into a component that had a 0.4 ns lifetime! A relationship with the carotenoids zeaxanthin and antheraxanthin was also established (see e.g., Gilmore et al. 1998). Then, in collaboration with the late Robert Clegg, and a visiting student from Germany, Oliver Holub (PhD, 2003),
Fluorescence Lifetime Imaging Microscopy (FLIM) was introduced, where they could see differences in lifetimes of chlorophyll fluorescence in single cells even though fluorescence intensity was the same. See the latest application of this lifetime of fluorescence method on Avocado leaves (Matsubara et al. 2011) where roles of both violaxanthin and lutein-epoxide cycles have been established.

\section{Tributes from friends, family and colleagues around the World}

Govindjee's dedication to the field of photosynthesis is known throughout the whole research community but he is certainly not all work and no play-far from it, Govindjee is full of life and enjoys taking part in all sorts of activities.

Figure 3 shows his photograph with some of his past graduate students (Julian Eaton-Rye ( $\mathrm{PhD}$, 1987), Late Prasanna Mohanty (PhD, 1972), George Papageorgiou (PhD, 1968), and Alan Stemler (PhD, 1974)) and with some of his research collaborators (Late Robert Clegg; Antony (Tony) Crofts; Michael Seibert (see Tribute below), and Colin Wraight (see Tribute below)). Figure 4 shows him with some of those he has associated with (Andrew Benson; James Barber; John Whitmarsh; Robert Blankenship, and Nancy King; see Tributes below). In addition, Fig. 5 shows his photograph with David Fork (with whom he wrote a biography of C. Stacy French (Govindjee and Fork 2006)); with several others (myself, Johannes Messinger (with whom he has written an educational review on PS II; see (Govindjee et al. 2010)), EvaMari Aro (see Tributes below); Imre Vass (with whom he wrote a review on thermoluminescence; see (Vass and Govindjee 1996)), and his lifelong partner Rajni Govindjee (with whom he has published papers including a Scientific American article (Govindjee and R. Govindjee 1974)); also shown is a photo with Roberta Croce (see the section on Tributes below) and Herbert van Amerongen; and the last photo shows him praising the songs of a young artist at the conference dinner of the 2013 Photosynthesis Research Conference in Baku, Azerbaijan (Allakhverdiev et al. 2013); also see a report by Allakhverdiev et al. (2012) for an earlier conference.

And so, in 2013 at 80 years young, Govindjee continues to edit books and contribute to original research articles. This represents 58 years of continuous scientific output and the sharing of an infectious enthusiasm for photosynthesis research and teaching. When Govindjee turned 75 in 2007 many of his students and colleagues contributed to an article celebrating his then 50 years in science (see EatonRye 2007b; also see Eaton-Rye 2007a). Extensive tributes were given then by graduate students and postdocs (Late Ion Baianu; Maarib Bazzaz; Carl Cedersrand; William 

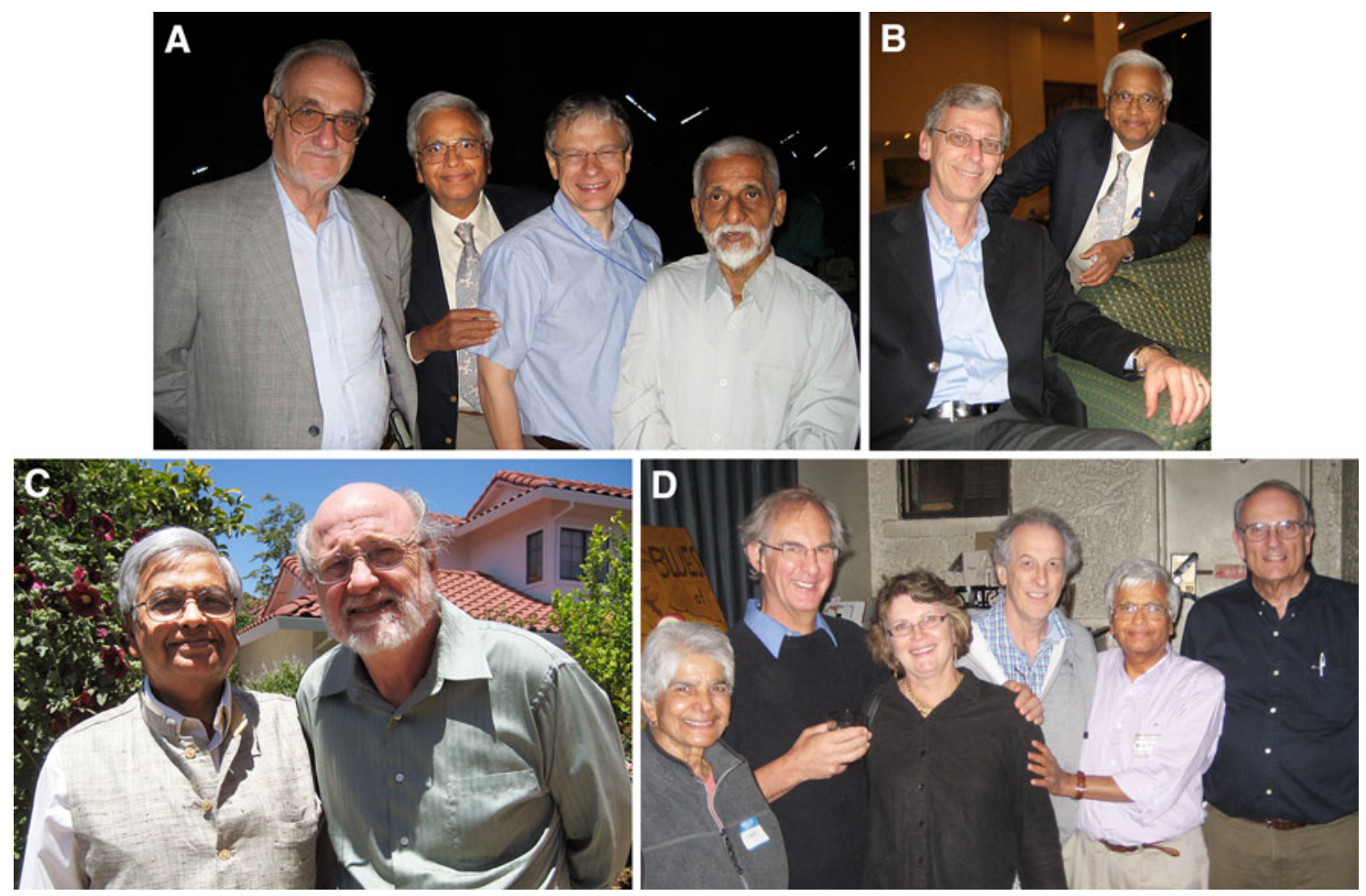

Fig. 3 Photographs of Govindjee with some of his former graduate students and colleagues. Top Left: Left to right: George Papageorgiou, Govindjee, Julian Eaton-Rye (the author) and Late Prasanna Mohanty. Top Right: Left to right: Michael Seibert and Govindjee; both these top pictures were taken in 2008 in Indore, India, at an International Congress, held in his honor. Bottom Left: Govindjee and
Alan Stemler; this photo was taken in Davis, California, in the 1990s. Bottom Right: Left to right: Rajni Govindjee, Antony Crofts, Christine Yerkes, Colin Wraight, and the late Robert Clegg; this photo was taken in 2010 at a get-together of Biophysics faculty and students at the University of Illinois at Urbana-Champaign

sent to me or to Govindjee from the community that he has helped shape over this long and productive career.

Coleman; Christa Critchley; Julian Eaton-Rye; Oliver Holub; Paul Jursinic; Rita Khanna; Late Prasanna Mohanty; John C. Munday; Subhash Padhye; George Papageorgiou; Srinivasan Rajan; Manfredo Seufferheld; Hyunsuk Shim; Alan Stemler; Wim F.J. Vermaas; Thomas Wydrzynski; Jin Xiong; Chunhe Xu; Xinguang Zhu; Barbara Zilinskas), as well as some of those with whom he had worked (Christoph Batory; Late Robert Clegg; Richard Sayre; Jack van Rensen; Michael Wasielewski). Further, the 2007 special volumes honoring Govindjee were published as volumes 93 and 94 of Photosynthesis Research; and had 47 articles and 123 authors. To recognize and remember these authors and their excellent contributions, and to say "thanks" to them, I have included a list of their papers in Appendix 2. These papers are still relevant to the field.

Also, I highly recommend a conversation of Donald R. Ort with Govindjee that was recorded for Annual Reviews, Inc. in recognition of his prominence in the field of Plant Biology. It gives us a glimpse into his research life, both personal and otherwise. You can see it at: <http://www. youtube.com/watch? $=$ cOzuLOvxEi0 $>$. Below I now include some, not all, of the many tributes that have been

\section{Tributes, arranged in alphabetical order}

Note: The tributes are not in quotation marks, but follow after the names of the authors. In some cases, I have added additional remarks-usually referring to joint publications between the author and Govindjee. These comments are within square brackets, followed by my initials (JJE-R) at the end.

\section{Charles J. Arntzen}

Professor, School of Life Sciences

Arizona State University, Tempe, AZ

The occasion of Govindjee's 80th birthday brings me back to the time when we were colleagues together at the University of Illinois at Urbana-Champaign in the 1970s. It was a wonderful period for research in photosynthesis, and Govindjee had inherited the "mantle of Robert Emerson" in the study of photosynthetic efficiency (right down to maintaining some of Emerson's original equipment for measuring quantum 

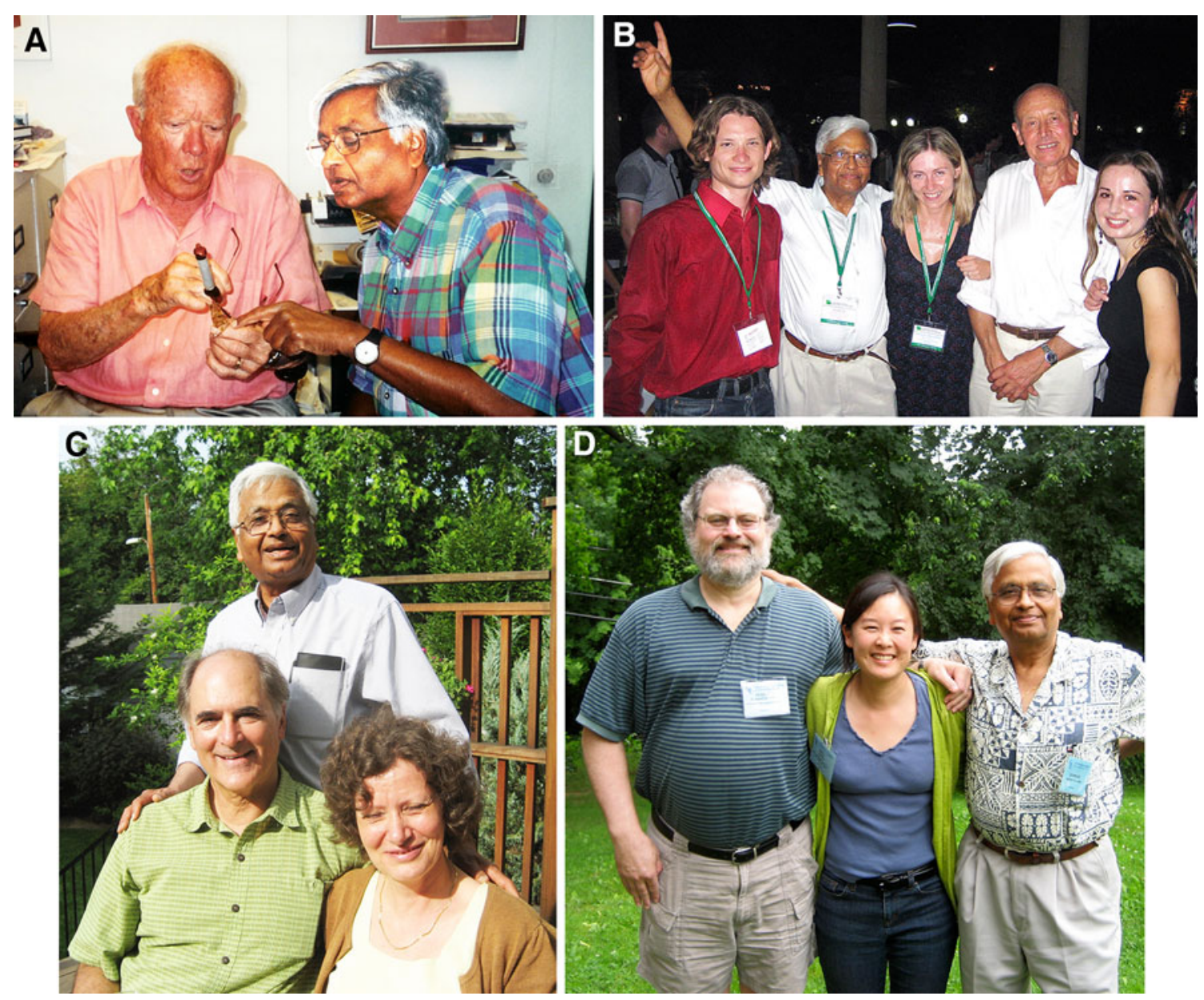

Fig. 4 Photographs of Govindjee with others. Top Left: Left to right: Andrew Benson and Govindjee; here Benson is showing to Govindjee a piece of equipment he used when he discovered, with Melvin Calvin, the C-3 cycle in photosynthesis. Top Right: Govindjee (second from left) with James Barber (fourth from left) and students

efficiency). Some of the questions being asked by the larger community at that time may seem curious or even impossible to today's generation of researchers-such as, are there 1,2 or 3 photosystems? I benefited greatly by my interaction with Govindjee, his students, and our multiple other colleagues who worked on questions of photosynthesis from field studies to quantum mechanics. And, this lively environment made it easy to attract coworkers from around the world to come and collaborate on projects of mutual interest. It was in this intense but delightful environment that my team identified mechanisms for herbicide resistance in the Photosytem II complex, which lead me to learning tools of biotechnology for genetic manipulation of proteins. But, this led me away from photosynthesis and into engineering of plants to create pharmaceutically active proteins, which I've done for the last 25 years. However, this time for celebration of Govindjee's career and life causes me to recall those wonderful years in Urbana in the 1970s, and work on chloroplasts and solar energy conversion. Happy Birthday, Govindjee! attending the 2011 Photosynthesis Congress in Baku, Azerbaijan. Bottom Left: Govindjee (standing) with John Whitmarsh (a longstanding friend and a former colleague) and Barbara Whitmarsh. Bottom Right: Left to right: Robert Blankenship; Nancy Kiang, and Govindjee)

\section{Eva-Mari Aro}

Professor of Plant Biology

University of Turku, Finland

Dear Gov-you are unique!

There are not many scientists who can compete with you: (i) in being such a big guy in photosynthesis research; (ii) in being so supportive, helpful and friendly with your colleagues irrespective of their reputation in science; (iii) in supporting young generation scientists; (iv) in having a never-ending enthusiasm for science and bringing that attitude to Turku; (v) in making me edit a book (thanks for that), and finally (vi) in being such a good friend to me.

[Eva-Mari Aro and Govindjee have published a research paper on mutagenesis of the D-E loop of the D1 protein (Mulo et al. 1997) and a conference report where they discovered that the thermoluminescence bands due to 

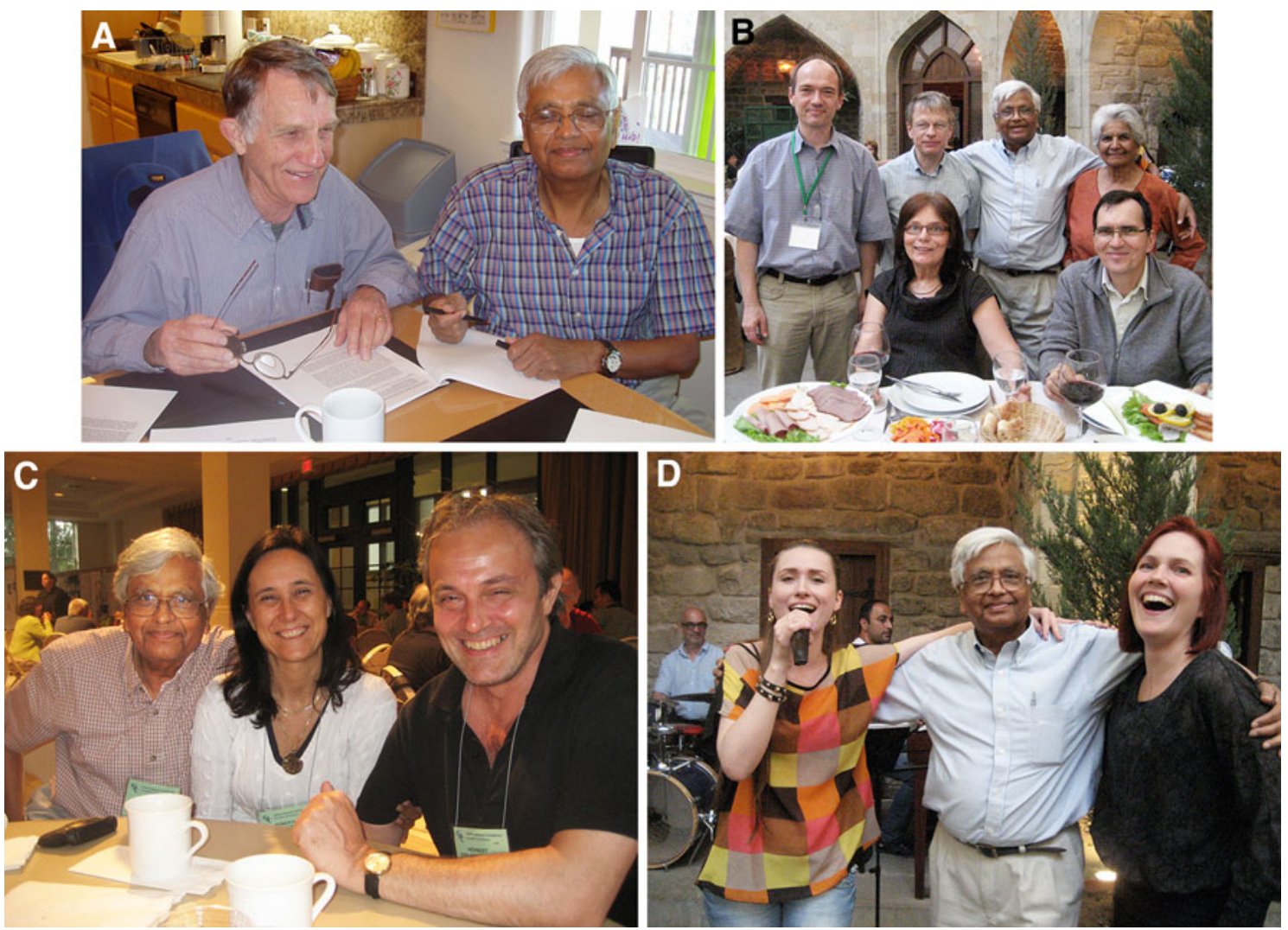

Fig. 5 Photographs of Govindjee with others. Top Left: Left to right: David Fork and Govindjee working on the biography of C. Stacy French (Govindjee and Fork 2006) for the Biographical Memoirs of the National Academy of Sciences, USA. Top Right: (standing) Left to right: Johannes Messinger, Julian Eaton-Rye, Govindjee and Rajni Govindjee; (sitting): Eva-Mari Aro, and Imre Vass, at a dinner at the

recombination of $Q_{\mathrm{A}}^{-}$with the $\mathrm{S}$-states were at the same temperature as that due to bands corresponding to recombination involving $Q_{\mathrm{B}}^{-}$in certain mutants of Synechocystis sp. PCC 6803, a rather unusual situation (Keränen et al. 1998); see Fig. 5... JJE-R.]

\section{James Barber}

Ernst Chain Professor of Biochemistry

Imperial College London

\section{Dear Govindjee}

I first became aware of you when I was a post-doc in Lou Duysens' laboratory in Leiden in 1967. Since then our paths have crossed many times. On all occasions you were an inspiration. I admired you not only as an outstanding and committed scientist but also for being so positive and enthusiastic. These characteristics are intrinsic to you and you remain active even to the grand age of 80 years. There is simply no one in our field who can match you for your
2013 conference on Photosynthesis and Sustainability, held in June, in Baku, Azerbaijan. Bottom Left: Govindjee with Roberta Croce and Herbert van Amerongen at the 2012 Gordon conference on Photosynthesis. Bottom Right: Left to right: Govindjee (center) enjoying the music sung by a wonderful Azeri artist (Alyona) and Marja Yatkin (from Finland)

contributions to photosynthesis, not only through your research work but as a disseminator of knowledge through your many review articles and books. You are truly a phenomenon and long may you continue to contribute to the subject, which you helped to mold from the day you started your $\mathrm{PhD}$ with two giants, Eugene Rabinowitch and Robert Emerson over 50 years ago.

\section{Congratulations}

[Barber and Govindjee have published one News Report (Govindjee and Barber 1980) and an opinion paper (Running on Sun) by the Royal Society of Chemistry, which is available at: <https://www.rsc.org/chemistryworld/2012/ 09/artificial-photosynthesis-sustainable-energy>. It deals with Artificial Photosynthesis, and was authored by M. M. Najafpour (Iran), J. Barber (UK), J.-R. Shen (Japan), G. Moore (USA) and Govindjee (USA) (Chemistry World, November, 2012, page 43); see Fig. 4... JJE-R.] 


\section{Maarib Bazzaz}

Retired Scientist, Harvard University

Lexington, Massachusetts

and

\section{Glenn Bedell}

Owner, Bedell Enterprises, LLC

Las Cruces, New Mexico

\section{Dear Govindjee}

I finally met Maarib, here in Boston, after all these $40^{+}$ years. We both wish you a Happy 80th Birthday! We want to thank you for all of your help to us over the past years as both graduate students and as former Ph.D. degree graduates. We have always held you and your professional accomplishments in the highest esteem. In addition to your outstanding scientific career, we both want to stress the fact that we have been especially impressed with your consistent efforts to acknowledge the contributions of previous authors who have contributed to your work in most, if not all, of the papers you wrote. Today, this seems to be a very rare professional quality among scientists.

Again, we want you to know that we both take great pride in having known both you and Rajni. Of course, we hope that you both have many more years of good health.

\section{With Greatest Regards}

[It is fitting to mention here one or two papers of Bazzaz and Bedell that they published when they were students in Govindjee's Lab since it shows the breadth of Govindjee's involvement in physiology of plants and algae. Govindjee's interest in the varied distribution and characterization of the two photosystems was fulfilled in Bazzaz and Govindjee (1973) when they found differences in bundle-sheath and mesophyll chloroplasts in maize, and this curiosity was heightened when they observed stark differences between wild-type maize and the olive necrotic 8147 mutant (Bazzaz et al. 1974), done in collaboration with another Professor, Dominick Paolillo. This led on to a later discovery by Maarib in Professor Tino Rebeiz's lab of divinyl chlorophyll $a$ ! On the other hand, Bedell and Govindjee (1966) attacked the problem of the minimum quantum requirement of oxygen evolution, as well as the existence of a two-light effect in deuterated algaesupporting Emerson, not Warburg. Although Govindjee's lab had never worked on photophosphorylation ever, his interest was sparked, as Govindjee once explained, when he and Rajni had carried out experiments, in 1962, with George Hoch at Baltimore, on the two-light effect in ATP synthesis (a work that they did not publish). Thus, Govindjee encouraged Bedell to find ways to measure ATP production in intact algae; for this, they used the luciferin-luciferase assay (Bedell and Govindjee 1973), but when Bedell left, none of his other students seemed interested in this area... JJE-R.]

\section{Andrew A. Benson}

Scripts Institution of Oceanography

La Jolla, CA

Govindjee is the center of Photosynthesis Research in the United States and the scientists of the World. All communications involving photosynthesis research pass through Govindjee's Filter. His efforts have been helpful, time after time.

[I refer the reader to what Govindjee has written on Benson at his 93rd birthday: see Govindjee (2010); he insists at any opportunity he gets anywhere that the Calvin cycle must be called the Calvin-Benson cycle because Benson's contributions were crucial to the discoveries that led to the 1961 Nobel Prize to Melvin Calvin; see Fig. 4... JJE-R.]

\section{Lars Olof Björn}

Emeritus Professor, Department of Biology

Lund University, Sweden

In 1957-1958 I worked in California as Dan Arnon's assistant. When I returned to Sweden, I told my Professor that I wished to continue with research on photosynthesis for my PhD. His reply was: "Now that Calvin has mapped the carbon assimilation pathway and Arnon has discovered photosynthetic phosphorylation in green plants there is nothing more to find out about photosynthesis. You should choose another topic." And so I had to do, and for the following 55 years I worked in other areas. But how wrong my Professor was! The scientific findings of Govindjee alone are more than adequate proof of this. My interest in the marvelous process of photosynthesis was not swept away easily, even if it was not possible for me to engage in it fully, and I continued to follow the literature. In my advanced age, when retirement has made it easier for me to choose my activities freely, Govindjee has helped me to fulfill some of my early ambitions. We have not met since a conference many years ago, but Govindjee has collaborated with me on several photosynthesis-related publications, and his immense knowledge has been an enormous asset in this activity.

Our joint publications deal with intriguing questions: Why chlorophyll $a$ (Björn et al. 2009a)? How did oxygenic photosynthesis evolve (Björn and Govindjee 2009)? Is there life in outer space (Björn et al. 2009b), and how did the Z-scheme evolve (Govindjee and Björn 2012)?

\section{Robert Blankenship}

Professor, Departments of Biology and Chemistry Washington University, St Louis, MO

It has been my pleasure to be a close friend and collaborator of Govindjee's for many years. He has made many 
important contributions to our understanding of photosynthesis. He has also had a profound impact on research in our field through his tireless efforts to edit a series of books that are extremely useful to students and researchers alike.

[Govindjee has always greatly valued Bob Blankenship's kind words about the Advances in Photosynthesis and Respiration book series at the time volume 25 (Chlorophylls and Bacteriochlorophylls) was released. He wrote: "Congratulations on another volume in the Advances in Photosynthesis and Respiration (AIPH) series. Govindjee's mentor Eugene Rabinowitch wrote the story of photosynthesis in the 1940s and 1950s. No one could ever hope to do that again; the amount of information is just too vast for any one person to ever hope to do a proper job of giving the real state of knowledge. However, Govindjee has really duplicated Rabinowitch's accomplishment in the only way it could be done nowadays, by enlisting editors who are experts in areas of the field and having them in turn enlist expert authors. When I look at the AIPH books on my shelf I am struck with how effectively they collectively summarize the field. I am continually impressed with how Govindjee has added new books to the series that make sense and really provide the level of detail that is needed" Source: $<$ http://www.life.illinois.edu/ govindjee/newbook/Quotation.html>; see Fig. 4... JJE-R.]

\section{Bob Buchanan}

Professor, Department of Plant \& Microbial Biology

University of California Berkeley, CA

\section{Dear Govindjee}

Your contributions in making the work of Andrew Benson better known will be long remembered.

[It was Govindjee who spent many days with Andy Benson, the co-discoverer of Calvin-Benson cycle for carbon fixation, and brought to light Benson's contributions; he brought Benson's work to the attention of the BBC that has produced a video "Botany: A Blooming History, Episode 2: The Power of Plants"; it fully recognizes Benson's contributions. There is also a entertaining chat by Govindjee with Benson at a web site; it was recorded by John Nishio; it can be seen at: http://www.life.illinois.edu/govindjee/index files/Andy\%20Benson_Asilomar_2002.mpg ... JJE-R.]

\section{Carl N. Cederstrand}

Retired from Beckman Instrument Company, Lives in Orange, CA

It gives me much pleasure to comment on my association with Govindjee during the time I was at the photosynthesis laboratory at the University of Illinois at Urbana-Champaign. Govindjee had so much enthusiasm for understanding photosynthesis that I believe his enthusiasm could have made photosynthesis work without chlorophyll.

[Carl Cederstrand's PhD was done essentially under the guidance of Govindjee. It was at the time when they provided one of the first papers on fluorescence characteristics of the two photosystems and the existence of different spectral forms of chlorophyll $a$ (Cederstrand and Govindjee 1961; Cederstrand et al. 1966a, b). It was Cederstrand who taught Govindjee how to drive a car and survived (see Eaton-Rye 2007b)... JJE-R.]

\section{Fred (W. S.) Chow}

Professor, College of Medicine, Biology and Environment Australian National University, Canberra, Australia

I have this little recollection of Govindjee:

I first met Govindjee in 1984, at a photosynthesis conference in Yangzhou, China, which Bacon Ke and Eric Lam also attended from overseas. I fondly remember Govindjee's effort to learn Chinese phrases. The first phrase he wanted to learn was "You la you ma?" (Is there any chilli sauce?), so that he could spice up his food. Since that meeting in China, Govindjee and I have been in yearly contact, usually around Christmas time. Indeed he came to Canberra for a sabbatical in 1998, and we joined forces with other colleagues to publish a paper in the Indian Journal of Biochemistry and Biophysics, as he insisted (Chow et al. 2000).

\section{Roberta Croce}

Professor of Biophysics and Photosynthesis

University of Amsterdam, Amsterdam, The Netherlands

I am looking at my first picture with Govindjee; it was quite some time ago but it seems that I am the only one that is getting older here. I was very proud to get a picture with the famous Govindjee but I am even more happy to have many more pictures with him now, which means that I have enjoyed his company and been overwhelmed by his enthusiasm for science many times. On top of his scientific achievements, Govindjee is a very strong catalyzer for the photosynthetic community, the guardian of our history and a great example of scientific passion. I am looking forward to our next picture!

\section{Henry Daniel}

Professor, Penn Dental Medicine

University of Pennsylvania, Philadelphia, PA

Govindjee's visit to Madurai many years ago changed my life and career! Because he dazzled us with his writing/ editorial/presentation and scientific accomplishments, I 
wanted to follow his footsteps and so joined the University of Illinois at Urbana-Champaign, declining other offers from UK and Europe. Even though I didn't pursue research in photosynthesis, I am still using the chloroplast system for various biomedical applications. In addition, I am now the Editor-in-Chief of the Plant Biotechnology Journal (ranked in the top 5 among 200 plant science journals), again following Govindjee's footsteps. So, I thank him for his leadership that profoundly influenced my life and career.

\section{Mrinmoyee Das}

Retired Professor of Chemistry

Kolkota, India

\section{Govindjee, as I know him}

I remember vividly the picture of my first meeting with Govindjee on the 14th of October 1965, around $10 \mathrm{pm}$, when my flight from Chicago landed at the Champaign airport. I had come from Kolkata, India, to join the research group of Eugene Rabinowitch at the University of Illinois at Urbana-Champaign; I was to be a post-doctoral research associate. The flight from London to Chicago was delayed by almost $7 \mathrm{~h}$ due to bad weather in London, and I was on the last flight for that day from Chicago to Champaign. This was the first time I was going abroad leaving my family and I was tense as I knew that Rabinowitch was in Europe at that time, and did not know whether anybody will come to receive me at that late hour. When I came out of the airplane, it was raining heavily. I, with my heavy overcoat, a handbag and still another bag, was all wet and could not see anything in the dim light of the airport; further my eyeglasses were wet. Suddenly, I felt that somebody came running towards me, took the bags from my hands, and asked me to run to the covered part of the airport. I was puzzled and could not understand which way to go. I felt that the person held my hand and asked me to run with him. When I came to the airport building, I found that a handsome young man, not much taller than I, was standing in front of me and introduced himself, " $\mathrm{Hi}$, this is Govindjee". I soon came to know that, at that time, he was an Associate Professor in the Department of Botany and Department of Physiology \& Biophysics at the University of Illinois at Urbana-Champaign. He drove me all the way to Urbana and reached his apartment, where I received warm welcome from Rajni, the pretty smiling wife of Govindjee. The next day, Govindjee took me to different offices of the University to take care of necessary paper work for my health and medical insurance, and to receive a part of my advance payment of my salary, since I was allowed to bring only eight US dollars from India. I was introduced to the different members of the department, and Govindjee invited me with his student group for lunch. I stayed in Govindjee's apartment for a few days till I got a place to live in one of the university dormitories and then to an independent apartment.

I hope that I will be excused for writing so much about myself, but this is the only way to describe Govindjee's kind and helping nature. Govindjee helped not only me, but all the newcomers to the photosynthesis laboratory, whether he or she belonged to his own research group or not. Although Ashish Ghosh, Gauri Shankar Singhal, Laszlo Szalay, Vitaly Sineshchekov, and G. Hevesy were also Rabinowitch's post-doctoral research associates, yet Govindjee helped them all in a similar manner as he helped me. (For a description of the then Photosynthesis Lab, see a personal perspective by Ghosh (2004).)

Govindjee himself had a large number of bright $\mathrm{PhD}$ students, coming from different parts of USA and abroad: John Munday, Glenn Bedell, Fred Cho, Ted Mar, George Papageorgiou, Prasanna Mohanty, Maarib Bazzaz, and many others. Govindjee was always very friendly to his students. There was camaraderie par excellence. They used to eat lunch together every day and during lunch discussed not only about their research work, but also about other topics. In addition, they used to meet every week in Govindjee and Rajni's home, where each student took turn in giving a talk about his or her work. Gauri Singhal and I had come from chemistry, and, thus, physiological and biological aspects of photosynthesis were quite new to us. Govindjee was kind enough to allow us to join their seminars, which helped us to learn a lot.

Govindjee and his students, especially Carl Cederstrand, Munday, Cho and Mar, had installed several new instruments for measurements of different aspects of photosynthesis. We were fortunate that Govindjee not only allowed us to use the new instruments, but discussed our results. Govindjee was and is a very good and a popular teacher; he had the ability to explain any difficult topic in a simple manner. He is extremely energetic, full of life, hard working and keen to work with new people and with new ideas. Although I was not in his research group, we did important research together and discovered that a longwave absorbing form of chlorophyll $a$ was responsible for not only the red drop in chlorophyll $a$ fluorescence, but for the F720 emission band at $77 \mathrm{~K}$ (Das and Govindjee 1967). It was fun to work with him. I end this short remembrance by mentioning that Rajni is a wonderful person; she was very friendly to me, and would invite me to their house frequently. I found that Govindjee was not only a renowned scientist but at home, he was a caring husband and an affectionate father to their two wonderful children Anita and Sanjay.

I pray for his good health, long life and an unending enthusiasm for educating the World about photosynthesis and its future role in solving the World's energy needs. 
Happy 80th birthday to Govindjee on behalf of all the past post-doc associates of Eugene Rabinowitch.

\section{Barbara Demmig-Adams}

Professor, Department of Ecology and Evolutionary Biology

University of Colorado, Boulder, CO

I first crossed paths with Govindjee in the mid 1980s at an international conference. I first met him in an elevator, and vividly remember his encouraging, excited smile and nod for my ideas - at a time when other experts in the fluorescence field accused me of "breaking the laws of thermodynamics" for suggesting that a carotenoid could quench singlet-excited chlorophyll. Govindjee is the scientist par excellence who combines the deep knowledge and sharp intellect of a world-expert with the joy and excitement of an ever-young mind marveling at new ideas. I am currently working with Govindjee on a book (DemmigAdams et al. 2014, in press) in his beloved series on advances in photosynthesis and respiration, and find myself marveling at Govindjee's insightfulness and wisdom on how to use a multi-authored book to move the understanding of a field forward in a leap-by facilitating crossfertilization, discussion, and reciprocal reviewing of warring author's work in ways far exceeding what is possible during standard scientific exchange.

\section{Jacco Flipsen}

Editorial Director, Life Sciences, Springer, Dordrecht

\section{Dear Govindjee}

I was introduced to you within the first few months in my career as a Publisher at Kluwer Academic Publisher, now Springer, back in the early summer of 1999. Passion for photosynthesis, and passion to communicate and publish about it were my first impressions, and that has never changed. Being the Editor-in-Chief of Photosynthesis Research and the continued involvement in the journal since, as guest editor of interesting special issues, Board member, Historical Corner Editor, author, and reviewer up to today are proof of that drive to communicate about science in general, and photosynthesis in particular. Also, still very active as Series Editor of the book series Advances in Photosynthesis and Respiration, where your contribution, and commitment to get the best in the field to write in the series is much appreciated. Lots of things have changed in those years, such as migration from print publication to online, initially for journals and now also books. Also we have seen changes from Kluwer, which was a relatively small publishing house, to Springer, a lot larger and therefore more having to rely on systems and (automatic) workflows. You have been able to change with this all, not without discussion I hasten to say. And I have always appreciated that discussion as it is coming from a good heart, looking for the best solutions. I very much appreciate our collaboration, and I hope for many years to come.

\section{Gyözö Garab}

Scientific Advisor and Principal Investigator Biological Research Centre, Szeged, Hungary

We feel lucky that YOU did get to be 80 and I would very much like to join the people celebrating you!

[Govindjee frequently cites a paper he published with Garab that showed already, in 1988 , that $\mathrm{CO}_{2}$ (bicarbonate) affects PS II in vivo (in leaves) (Garab et al. 1988). Currently, Govindjee is co-editing a book with Győző Garab, Barbara Demmig-Adams and William Adams on a topic that is now close to his heart: it deals with Non-Photochemical Quenching (or NPQ) of the excited state of chlorophyll $a$ and dissipation of excess energy as heat in plants, algae and cyanobacteria; it will be published in 2014 in the Advances in Photosynthesis and Respiration series... JJE-R.]

\section{Alex Goloff}

Retired Research Scientist

St. Charles, IL

\section{Govindjee-A celebration perspective}

Govindjee is a greatly admired friend who is difficult to emulate because his mastery of so many things is like a colorful landscape painted by the best. He can cast a spell on misconception and enlighten the gifted as well as embrace the neophyte. He has sparked the desire in me to think differently and broadly and pursue a topic of interest without hesitation, but tempered by prudent thought and observation. Govindjee knows the subtleties of science which, to me, are encapsulated in Carl Young's quote: "The pendulum of the mind alternates between sense and nonsense, not between right and wrong" (and) "knowledge rests not upon truth alone but upon errors also".

Govindjee is a great communicator and a great thinker for he has mastered the ability to create knowledge as well as disseminate knowledge. He understands the sparks needed to ignite the mind of the languid and he knows what is needed to make the brash and zealous tamed diplomats. Govindjee champions anything that might inspire those on the road to discoveries, including thoughts from the ancients, prose from the fields of poetry, wisdom from the scripts of philosophy, or notes from music of the greats.

Govindjee knows that the tales from the history of science are a proven compass for things to come and a shield 
from the marching minds to misguided drums. A discussion with Govindjee enhances inspiration while concepts and thoughts are congealed and imagination becomes closer to reality. Govindjee is a man by example. Govindjee is a mind by example. Govindjee leads by example.

Govindjee, each candle lit for you is in celebration of your 80th birthday as well as your venerated achievements in science. You are archived in the minds and hearts of all of us, and in the minds and hearts of generations to come.

\section{Ulrich Heber}

Emeritus Professor, Department of Botany

University of Würzburg, Germany

What is a dominant trait in a researcher's personality? Single-mindedness! What is it in a professor's personality? Broad-mindedness! How to characterize Govindjee in one word? Impossible, because he is both, broad-and singleminded in one person at the same time! The balance between broad- and single-mindedness depends on occasion, mood, subject, job at hand and partner. When challenged by his own inner drive or a partner, he is a dedicated researcher or an able teacher, a competent discussant and even a propagandist of his convictions on the subject under discussion. What is his main interest? Clearly photosynthesis! The problem is that photosynthesis is a world by itself. To fully understand photosynthesis is impossible. To come close to understanding is great achievement. Govindjee is one of the few who can boast close understanding. Even to come close one needs to be simultaneously a biologist, a chemist, a physicist, an ecologist and even a mathematician. What is Govindjee to photosynthesis? The biochemist? The biophysicist? The historian? He is all of that. To master the different disciplines of natural sciences, lifelong learning is indispensable. God gave Govindjee a long life. He used it competently. Although being by now 80 years old, he still carries on. He is still actively involved in research and in writing.

When and how did I meet Govindjee? For several decennia, I watched him from a distance, seeing him at conferences and reading his many contributions to photosynthetic research and to the photosynthetic literature with great profit. Unfortunately, I am not a good reader. Once, I was severely criticized by an unknown referee who was more knowledgeable of the literature than I was. Was it Govindjee? I suspect he was. He was right in his criticism. His command of the literature is famous. Closer acquaintance with him needed the passage of time and also courage. I am fearful of great men. At a meeting in Passau in Germany, about a year or so ago, Govindjee approached me asking innocently "How old are you?" That broke the ice. I lost fear. I always suspect that my peers must be far older than I am. Now it turned out that I am his senior, at least by age, certainly not by experience. My confidence returned. Now, perhaps, we are on some more equal footing than earlier. I wish him for his birthday continued pleasure and success in what he is doing and a little free time to look back at a fulfilled life as one of the pioneers of photosynthesis.

\section{Jane F. Hill}

Botanist and a Historian of Science Bethesda, MD

In addition to his own major contributions to photosynthesis research and the history of that research, Govindjee has been a mentor and inspiration to many students and researchers in both areas. He has guided me, and many others, with unfailing encouragement and support. He encouraged me to pursue my interest in the early pioneers of photosynthesis research, culminating in a chapter that I wrote on the subject for volume 34 (Photosynthesis: Plastid Biology, Energy Conversion and Carbon Assimilation) of his series Advances in Photosynthesis and Respiration (edited by Julian Eaton-Rye (author of this article), Baishnab Tripathy (a former student of his former student late Prasanna Mohanty) and Thomas Sharkey (who is co-editor, with Govindjee, of the series)). Subsequently, he provided me further encouragement and guidance when I told him of my interest in translating from French into English an 1804 book by the Swiss plant physiologist Théodore de Saussure, who was the last of the early photosynthesis pioneers. That translation, for which he graciously contributed a foreword, included a lengthy introduction and other background material prepared by me. It was published in 2013 by Springer as "Chemical Research on Plant Growth: A translation of Théodore de Saussure's Recherches chimiques sur la Végétation".

\section{André Jagendorf}

Emeritus Professor, Department of Plant Biology

Cornell University, Ithaca, NY

Govindjee has made important contributions to the analysis of photosynthetic mechanisms, over the whole of his professional life. His work has been especially useful in defining the role of carbon dioxide in Photosystem II, and in the insightful use of fluorescence transients. However, I think an even larger contribution has been in prolific and highly extensive writing and editing. Partly this was through his efficient editing of the journal, Photosynthesis Research; it was partly done by organizing many symposia, and monographs. His exposition of photosynthetic mechanisms, his bringing in the writings by an enormous number of scientists, has helped all of us understand much more about the integrated processes involved in 
photosynthesis. He has, to a large extent, become the glue bringing together many workers and many aspects of this important section of plant biology. I think of Govindjee as being the heart of the community. We are all grateful for his energy and enthusiasm in unifying our field.

\section{Wolfgang Junge}

Professor Emeritus of Biophysics

University of Osnabrück, Germany

\section{Dear Govindjee}

You have contributed over almost six decades to the success of photosynthesis research, starting from the first glimpses at reaction centres in the late fifties of the last century on to your supposedly last word in 2012 on the multifarious roles in photosynthesis of bicarbonate.

Your comprehensive knowledge of this research field has been balanced by an all-embracing intimacy with the rich spectrum of personalities within. Without your initiative and great effort their personal perspectives had hardly been told. We owe you a lot!

Please, accept "meine herzlichen Glückwünsche zu Deinem 80-sten Geburtstag", and my admiration for your rich life!

[Govindjee's association with Wolfgang Junge goes back many years into the 1970s. With his PhD student Rita Khanna, Govindjee went to Junge's lab in Berlin and they provided the very first measurement showing involvement of bicarbonate in proton uptake and release (see Khanna et al. 1980). Several black and white photographs of Junge appear in a historical article Govindjee wrote (Govindjee and Yoo 2007)... JJE-R.]

\section{Nancy Kiang}

National Aeronautics and Space Administration (NASA)

Goddard Institute for Space Studies

New York, NY

As a young postdoc exploring outside my field of biometeorology, with burning curiosity about the reason for the vegetation "red-edge," and with no one to speak to about this, I came across an old textbook figure of absorbance spectra of photosynthetic pigments. The credit was [given to] Govindjee, so I desperately tracked him down. That happy contact led to my introduction to the wonderful community of photosynthesis researchers, whose characteristic collegial and nurturing interactions surely are so because of Govindjee's warm and enthusiastic influence. Govindjee and I eventually updated that early figure, and co-authored two very well received papers (Kiang et al. 2007a, b), which further led to a Scientific American article and now an online database of biological pigment spectra. I am happy to add walking the Great Wall ${ }^{2}$ of China with Govindjee to my list of milestones. Thanks to Govindjee (see Fig. 4) for getting me on my feet and into the inspiring world of photosynthesis, the science and the people.

\section{David Knaff}

Editor-in-Chief, Photosynthesis Research

Professor of Chemistry and Biochemistry

Texas Tech University, Lubbock, TX

It is a distinct pleasure to contribute a few personal remarks about Govindjee on the occasion of his 80th birthday. When I agreed to become the editor-in-chief of Photosynthesis Research, I did so with considerable trepidation. This was in part because I would be succeeding Bob Blankenship and, given the outstanding job Bob had done during his tenure as editor, I knew that matching his performance would be no small task. On top of that, I could not avoid thinking of the fact that the bar for defining a successful editorship had already been set at a very high level in the earlier time when Govindjee had served as editor of the journal. During his time as editor, he made enormous contributions towards solidifying the position of the journal as a publication involving very high standards and as a place where one might read about the most exciting new developments in the field. After his term as editor ended, he continued (and still does to this day) making an important contribution to the journal by serving as the editor of its Historical Corner, where his work continues to remind us of the enormous contributions to our field made by investigators in the past. I should also mention that he managed to do much of this while not only continuing a successful career as an active researcher but that he also served as the founding editor for Springer's book series, Advances in Photosynthesis and Respiration. He served for many years as the senior editor for this very successful and influential series of monographs and, as I learned when I served as a co-editor for one of its volumes, Sulfur Metabolism in Phototrophic Organisms, he really was the driving force for keeping it at the forefront of our field and using his considerable organizational skills to insure that volumes appeared on time and at a very high level of quality. I congratulate him on his many contributions and look forward to his future ones.

[It is also of note that Govindjee has written a history not only of the journal Photosynthesis Research, but of another journal Photosynthetica (see Govindjee et al. 2002); he has

\footnotetext{
${ }^{2}$ I would like to add that at the time of checking the proofs, I received an e-mail with the following interesting description of Govindjee: "China has the Great Wall, but Photosynthesis has the Great Govindjee"; it was sent by Saber Hamdani, in Xinguang Zhu's lab in Shanghai, China, who Govindjee had met only recently and that too for a few days... JJE-R.
} 
also written one editorial with David Knaff (Govindjee and Knaff 2006)... JJE-R.]

\section{Elmars Krausz}

Professor, Research School of Chemistry

Australian National University, Canberra, Australia

\section{Happy birthday Govindjee}

Having known you just one of your eight decades, I do admire your energy, enthusiasm and humor. I think of the saying "it is easier to string the moon and the stars together than to live this life to the fullest".

I know your efforts in making the most of life are both sincere and effective. I treasure your friendship and wish you more of the same for the next decade.

\section{Best wishes}

\section{Ashwani Kumar \\ Emeritus Professor \\ University of Rajasthan, Jaipur, India}

Mahatma Gandhi once said, "My life is my message". This is absolutely true for Govindjee's life and that of his wife Rajni (whom I call Rajniji, with respect). Govindjee has devoted his life to educate people globally, bring new ideas, develop themes and hypotheses, proving them with experimental acumen, and Rajniji has silently but firmly worked on similar lines in all the different roles and today [written on July 24, 2013] what I observed has left a deep mark on me; unmindful of her well being, she lent helping hand to a needy woman, who had fallen in her front yard, and Govindjee showed a great human touch. Even thousand volumes in their praise as scientists and as good human beings will be less. I learned a lot from the masters of the subject today and to say thanks will be much too less for me. Since I had read the beautiful 1969 book of Govindjee with Eugene Rabinowitch, and after I saw today, in his office, the 35 edited volumes of Advances in Photosynthesis and Respiration, produced under his guidance, I am highly impressed with his dedication to Photosynthesis Education. To me, this is real success.

My wife always tells me that only the tree, which bears fruits, has its branches bent because of the weight of the fruits. I have seen this in Govindjee and Rajniji. They are laden with fruits of success and achievement, yet they never boast of them and always treat people humbly. This is true embodiment of greatness. I once read "greatness" is better, but gratefulness is much better. In the Govindjees, I have found this quality, and that too for the first time in my life. They harbor no grievance against any person and are ready to go long ways to help people everywhere in the world. We wish them a long, meaningful, productive, prosperous, peaceful and fruitful life. I wish Vijay (i.e., Victory) to Govindjee on his 80th birthday celebration on October 24, 2013, by the journal Photosynthesis Research (being edited by Suleyman Allakhverdiev (of Russia), Gerald Edwards (of USA), and Jian-Ren Shen (of Japan)) that he has served with dedication over the many years.

When I started learning about photosynthesis from my father Late Swami Dayal Tewari, who had received his Master's degree in Botany, from Allahabad University (the same University where Govindjee later received his Master's degree in Botany, in 1954), I was made aware of Blackman's law of limiting reactions: it seemed to be the most important concept for the understanding of photosynthesis. For me, Rabinowitch and Govindjee's 1969 book provided, for the first time, basic understanding about it, and the rest of the many concepts in photosynthesis, and that in simple terms. I cherished it then and I cherish it now.

Over 50 years ago, the 1931 Nobel-laureate Otto Heinrich Warburg discovered a unique stimulatory role of $\mathrm{CO}_{2}$ in the Hill reaction (i.e., $\mathrm{O}_{2}$ evolution accompanied by reduction of an artificial electron acceptor), which, obviously, does not include any carbon fixation pathway. Warburg had used this discovery to support his idea that $\mathrm{O}_{2}$ in photosynthesis originates in $\mathrm{CO}_{2}$. During the $1960 \mathrm{~s}$, a large number of researchers attempted to decipher this unique phenomenon, with limited success. In the 1970s, Alan Stemler, Govindjee's PhD student, perfected methods to get highly reproducible results, and observed, among other things, that the turnover of Photosystem II (PS II) was stimulated by bicarbonate ions (hydrogen carbonate): the effect would be on the donor or the acceptor, or both sides of PS II. In 1975, Thomas Wydrzynski, also Govindjee's PhD student, discovered that there was a definite bicarbonate effect on the electron acceptor (the plastoquinone) side of PS II. The most recent $1.9 \AA$ crystal structure of PS II from Japan (from the research group of Shen and Kamiya), unequivocally shows bicarbonate bound to the non-heme iron that sits in-between the bound primary quinone electron acceptor, $Q_{\mathrm{A}}$, and the secondary quinone electron acceptor $Q_{\mathrm{B}}$. (See Shevela et al. 2012, for a review.) To me, this discovery, in addition to its well-known role in carbon fixation, of the unique role of bicarbonate/ $\mathrm{CO}_{2}$ on the electron acceptor side of PS II, by Govindjee and coworkers (including Julian Eaton-Rye, author of this Tribute to Govindjee), is a major discovery, and we owe this to Govindjee's ingenuity, persistence, and drive unmatched in the history of photosynthesis research. I marvel at this research and I believe that he will go down in the history of photosynthesis research for this unique finding.

John C. Munday, Jr.

Professor of Natural Science and Mathematics

Regent University, Virginia Beach, VA 


\section{Tribute to Dr. Govindjee}

Graduate study is a special time of life. The opportunity to be immersed in research on a topic of choice, after years of preparatory schooling, is a time of deep intellectual reward. My choice to study photosynthesis was largely because of its biophysical complexity. The research methods enabled "seeing" events at the molecular level and gaining insights that could explain a process basic to all life on earth.

Choosing a major professor was a major decision. On reflection about the options in the Photosynthesis Laboratory at the University of Illinois, I concluded that Dr. Govindjee would be a wise mentor, a steady hand of guidance, and an encourager. He had already proven his skill at research and his deep knowledge of the field of photosynthesis.

Dr. Govindjee provided a list of problems where he believed that research would bear fruit. This suited my temperament and level at the time. After some investigation I developed a proposal, "owning" the content as my own; but later, looking back, I realized that he had foreseen my proposal exactly as one from his original list. $D r$. Govindjee proved to be an exceptionally wise mentor. He was full of patience, manifested fully a teaching spirit, and with painstaking care instilled a sense of excellence and quality in research. He demonstrated in his own research what he strove to teach.

He was ever-present in the laboratory. Always with a cheerful smile, and obviously enjoying research, he made the laboratory a place where students, research associates, and visiting faculty wanted to be. He organized seminars in the lab and at his home. His wife Rajni had the gift of hospitality and we enjoyed her refreshments. (She also made significant contributions of her own in photosynthesis research, and cared for their young family.)

Along the way his comments and critique about my research were the stimulus for pushing forward, solving problems, and thinking creatively. I distinctly remember various points he made about how to do quality research. And in a final exam, he defended this student against a visitor's mistaken claims about unpublished research from abroad, pointing out the core principle that what counts in scientific advance is peer-reviewed publication. In this and other ways, his great skill in building up all his graduate students facilitated our professional fruitfulness and gave us confidence for the future.

Looking back over his distinguished career, and the large number of students he guided, we can see the consistency in his research productivity and his mentoring skill. Even in retirement he works to continue his contributions, and to remain in contact with all his students from over the years.

The ongoing freshness of his spirit is inspiring. He is a most remarkable man. Dr. Govindjee, I salute you, and have great joy in honoring you and the richness of your life.
[John Munday was one of the first $4 \mathrm{PhD}$ students of Govindjee; others were George Papageorgiou, Fred Cho and Ted Mar); Munday made crucial experiments that led to an early understanding of the fast (OPS) fluorescence transient in the green alga Chlorella: see Munday and Govindjee 1969a, b; whereas Papageorgiou and Govindjee (1967, 1968a, b) and Mohanty et al. (1971) made crucial experiments that led to an early understanding of the slow (SMT) fluorescence transient in the cyanobacterium Anacystis nidulans, Chlorella pyrenoidosa and the red alga Porphyridium cruentum. In addition, Mohanty et al. (1970) provided the first measurement that was related to the so-called newly discovered "state changes" from the laboratory of Norio Murata and of Jack Myers... JJE-R.]

\section{William L. Ogren}

Leader, Photosynthesis Research Unit, US Department of Agriculture (retired)

Former Professor, Departments of Agronomy and of Plant Biology

University of Illinois at Urbana-Champaign

Govindjee's life history and many accomplishments have been thoroughly and exceptionally well summarized by his former students and colleagues (Eaton-Rye 2007a, b, 2012; Clegg 2012; Papageorgiou 2012a). I want to use this opportunity to relate a few of my personal experiences rather than reiterate this voluminous information.

I first met Govindjee in June 1965 when I interviewed for a U.S. Department of Agriculture position in the Department of Agronomy at the University of Illinois. Trained as a biochemist in David Krogmann's laboratory, then located at Wayne State University in Detroit, I was pretty much mystified by the biophysical lingo Govindjee threw at me even though given in his usual charming manner. I was offered and accepted the position and moved to Urbana in October. Govindjee immediately invited me to participate in the weekly photosynthesis seminar moderated by him, Eugene Rabinowitch and Chris Sybesma and with some trepidation I did so. Initially it was a tough slog, but eventually some of the biophysical concepts started to make sense and sink in.

The Urbana photosynthesis seminar at that time comprised the light reactions and only the light reactions. As the sole person interested in carbon fixation, this subject was pretty much outside the purview of my group. Fortunately in the late 1960s and early 1970s there was a strong renaissance in research on photosynthetic carbon fixation arising from the discovery of $\mathrm{C} 4$ photosynthesis by M.D. Hatch and C.R. Slack and the beginnings of serious interest in photorespiration and its potential impact on agricultural productivity. Also during this time George Bowes, 
Raymond Chollet, and then Bill Laing joined my laboratory, increasing the presence and voice of carbon fixation on the campus. With the confluence of these events I was able to persuade Gov that his students needed to learn about the dark side of photosynthesis, and he agreed that I should organize a semester of the seminar on carbon metabolism. Because of the seminar's historical focus on biophysics and the light reactions, I wondered how this would really work out. One incident epitomizes my perception of how Gov viewed the role of carbon metabolism in the overall context of photosynthesis at that time. I had selected a paper from Peter Homann's laboratory (Salin and Homann 1971) that suggested there was more photorespiration in old leaves than in young leaves, and assigned a graduate student to present a formal seminar on it. A few minutes after the student began, Govindjee spoke out "Why is the name Peter Homann familiar to me?" The somewhat startled student stopped talking, and I motioned to him to resume. A few minutes later Govindjee again spoke out, "I think I should know this Peter Homann." At this point I turned to Govindjee and said that Peter Homann had been a student of Hans Gaffron and now had his own laboratory. Somewhat relieved, Govindjee responded, "Oh, THAT Peter Homann, the one who used to work on photosynthesis." I could only sigh and ask the student to continue.

Govindjee has published many significant papers on various aspects of photosynthesis, mostly regarding Photosystems I and II. Not being particularly engaged with the light side of photosynthesis, in my mind I consider his prolific editorial activities to be his defining contribution to the field. He was the first US co-editor of the journal Photosynthesis Research in the early 1980s, and was able to attract superior papers. He was the founding editor of the highly successful series Advances in Photosynthesis and Respiration, now in its 36th volume. But I look most fondly at the personal histories he solicited and edited. In the mid-1980s he created and established a Historical Corner in Photosynthesis Research and persuaded various luminaries to write about their research breakthroughs. In the early 2000s he greatly expanded this effort by editing three issues of Photosynthesis Research devoted exclusively to this topic, articles that were subsequently published in book form ("Discoveries in Photosynthesis", edited by Govindjee et al. 2005). Thus scientists and students, as well as future historians, have access to an enormous resource of first hand reports on most of the major discoveries in photosynthesis since the last half of the twentieth century. To consider gathering this kind of information on such a scale required remarkable acuity, and I am unaware of any other major discipline whose progress has been so thoroughly documented. I consider soliciting and collecting these memoirs to be a brilliant accomplishment.
It has been a great joy to know and at times collaborate with Govindjee over nearly the past half-century. He has been an inspiring colleague and a magnificent force in photosynthesis research. On the occasion of his 80th birthday I wish him continued success in all of his many endeavors.

[There are two things to mention here: (1) a research paper Ogren and Govindjee published together, it was Spalding et al. (1984) - and dealt with both $\mathrm{CO}_{2}$ and the light reactions; and (2) the article Govindjee wrote, with Archie Portis, on William Ogren (Portis and Govindjee 2012), when he received the Rebeiz Foundation's Lifetime Achievement Award for Excellence in Basic Sciences in 2011 http://www. vlpbp.org/ltaawardogrenceremony091011a.html-Govindjee had been its very first recipient... JJE-R.]

\section{Anju Okhandiar}

Gordon, Berwickshire, UK

I have known Professor Govindjee since my childhood. He is a wonderful person. He is my maternal Uncle.

In my view he is a true Scientist. He has the ability to inspire others and within a context this has allowed development to take place, based on reason and the search for truth inevitably leading to the betterment of all Society and Humanity.

His thirst for knowledge, its applications at present and its implications for the future exhibit his true ingenuity.

An amazing fact about Govindjee is his untiring and uncompromising work schedule. His success pertinently mirrors his individualistic, innovative and unparalleled contributions that he began years ago in the field of Plant Biology, in particular-Photosynthesis. He still continues to write and make contributions to his field relentlessly.

Govindjee has impressed me since my childhood. I remember he would bring me beautiful books when he visited us in India. Not to mention the many gifts that I have received from him over the years.

As an elder learned family member he has always shown the path that has had a positive influence over my education and work. I admire him greatly. I find his honesty, generosity, kindness and his original wit as truly remarkable qualities. I wish him Love, Peace, Happiness and Best Regards on his 80th Birthday.

\section{Bill Rutherford}

Professor in Biochemistry of Solar Energy

Imperial College London

Bill to Gov:

Happy Birthday, Govindjee. 
Good health, Professor G, all the best...

\section{Reminiscences}

When I arrived in the University of Illinois (as a Postdoc in Tony Crofts lab) (more than 2 weeks later than expected) there were three messages on my desk "Dear Bill, welcome to U of I, your seminar will be on Monday at 4 o'clock, all the best, Govindjee", the second one was the same but started, "since you missed your last seminar it has been rescheduled for next Monday" and the third message was the same again but a rescheduling for the next Monday which was coming up.

First impression: Gov has enthusiasm and persistence.

Later in Urbana, I was hunting for a strong light for my experiments and I was touring the university with a power meter. Govindjee said he had just the thing and disappeared into the heirlooms cupboard. He came back with something that was certainly of great age and sentimental value and looked like it had come from a pre-war setup or possibly a watchtower at Joliet prison. He cranked it up and pointed it at my hand-held power meter which duly melted as all the hair on the back of my hand was incinerated: clearly a portable death ray lamp. I politely declined the offer (and went back to nicking the big Kodak projector from the Chemistry lecture theatre).

Second impression: Gov is helpful and sentimental but can be "dangerous".

When I turned up in Japan in 1983 to follow up on my identification of the thermoluminecence bands of the year before, Govindjee and Gernot Renger were there. I published several articles, some with $\mathrm{G}$ and $\mathrm{G}$, and we had a lot of fun (see Rutherford et al. 1984). Indeed fun was had out of the lab as well as in: with $G, G$ and me, our respective wives, Rajni, Eva and Agnes and our enormously hospitable Japanese hosts, Inoue san and the gang. I have good memories of parties in and around Tokyo and of course in Indian restaurants. And with Gov smoking a fat cigar*:

Third impression: Gov knows how to enjoy himself and entertain his friends.

(*An exchange at a party in Japan: Bill to Gov: "you see this (obviously chocolate) ice cream"? Gov: "yes?" Bill: "well it was vanilla until you lit up that cheroot!" [We all know that Govindjee stopped smoking around that time... JJE-R.])

I could go on about the famous incident at the hot baths in Hakone but this is not the time for discussing the combination of Japanese bathing culture, Govindjee's photographic mania and some unexpected optical phemonena involving the refraction of light through water. I will leave that to your imagination. Many of us still have copies of the photos stored away.

Forth impression: Govindjee likes to preserve history (in the form of photos).

All the best, Gov, keep on with your enthusiasm, your helpfulness, your sentimentality, your photography, and keep on enjoying yourself.

\section{Richard Sayre}

Senior Research Scientist Los Alamos National Laboratory, Los Alamos, NM

As an early stage assistant professor I had the privilege to work with Govindjee for the first time. He brought incredible excitement, innovation and energy to our joint project. My students could hardly keep up with him. As I came to know Govindjee, I realized he had always been like this even after his retirement from Illinois. There are few who have been so impactful on the field and the early careers of young scientists in photosynthesis. I hope we can all aspire to his model. Best wishes for your 80th birthday.

[It is fitting to mention here the extensive collaborations that Sayre and Govindjee had. I refer the readers to read their joint publications on mutants of Chlamydomonas reinhardtii that showed the importance of specific amino acids on the donor (Roffey et al. 1994; Kramer et al. 1994) and acceptor sides of PS II (Hutchison et al. 1996; Xiong et al. 1997)... JJE-R.]

\section{Michael Seibert}

National Renewable Energy Laboratory Golden, CO

Recollections on working with Govindjee on the occasion of his 80th birthday

I got an unexpected call from Govindjee in the spring of 1988. Having known him for years and having admired him for his enthusiasm, energy, and knowledge of both the history of photosynthesis and its extensive literature, it was clear that he was very excited about something. After some pleasantries and with some hesitancy (very un-Govindjeelike), he revealed that he had reviewed a paper that we were publishing on problems with the Nanba/Satoh Photosystem II (PS II) reaction center (RC) preparation (Nanba and Satoh 1987). It turned out that the prep was quite unstable (Seibert et al. 1988), and Govindjee, working with Mike Wasielewski, found that they could not make a successful picosecond kinetic measurement of the primary charge-separation event 
in the PS II RC material that was being made in Urbana, because of its inherent lability. We had surmounted the problem and demonstrated that it could be stabilized long enough for spectroscopy to done on functionally intact PS II RCs. Govindjee quickly catalyzed a collaboration among the three of us (the fact that he did this rather than using privileged information to try to make the new preps himself in Urbana underscores his character as a person) that lasted for a decade, and we soon met at Argonne National Laboratory to make the first direct measurements of the primary charge separation rate in stabilized, isolated PS II complexes (Wasielewski et al. 1989). It was great fun meeting in Chicago over that period of time for intense laboratory sessions (the preps were from NREL (National Renewable Energy Laboratory), the picosecond laser system was Argonne's, and the coordination was by Govindjee), trips to Indian (led by Govindjee) and Japanese (led by Mike W.) restaurants, late evening returns to the lab to tweak the system and get more data (Govindjee spent more than one night sleeping on the table outside the lab to be able to spell us as necessary), and last minute rushes to get to the airport on time were the rule. By the way the restaurant trips were often unsuccessful due to "early restaurant closures" on our timescale. We also survived the "Tiger Team" inspections in 1991 (safety was a major issue in the national laboratories at that time and a new Secretary of Energy was on the war path to ensure compliance) and there were many interruptions in the laser experiments due to accidental tripping of the laser lab door interrupt system. Without discussing the outcome of the work in detail (those interested can read a historical commentary (Govindjee and Seibert (2010)), we always enjoyed the camaraderie of meeting with Govindjee about 3 times a year along with the many stories that he related about the early giants of photosynthesis (including Robert Emerson, Eugene Rabinowitch, Otto Warburg, and Melvin Calvin). It was the personal observations that were never written down about the personalities and battles associated with these figures that Govindjee could tell so well that is of great value historically. Finally, Govindjee has an amazing ability to remember scientific detail, know how people in the field fit together, and successfully mentor young people in science.

\section{Thomas D. Sharkey}

Professor, Department of Biochemistry and Molecular Biology

Michigan State University, East Lansing, MI

Govindjee as editor, a tribute on the occasion of his 80th birthday

Much has been written about the contributions of Govindjee to understanding the intricacies of photosynthetic electron transport, but I would like to pay tribute to Govindjee as editor. While many have interacted with Govindjee as editor of one or another volume, I have had the privilege to work with Govindjee on the Advances in Photosynthesis and Respiration-Including Bioenergy and Related Processes from volume 31 to plans for volumes that currently reach in the early 40s (Volume 37 Photosynthesis of Bryophytes and Early Land Plants edited by David T. Hanson and Steven K. Rice is in the proof stage, Volume 38 Microbial Bioenergy: Hydrogen Production, edited by Davide Zannoni and Roberto De Phillippis is in the submission stage in July 2013).

Govindjee has been fascinated with photosynthesis from very early schoolboy days in India. Coming to the hotbed of photosynthesis research at Illinois resulted in Govindjee working with many of those who made the fundamental discoveries and led to Govindjee's own scientific contributions. Photosynthesis is a broad topic and Govindjee was impressed by the comprehensive treatment by Eugene Rabinowitch (http://archive.org/stream/ photosynthesisre01rabi/photosynthesisre01rabi_djvu.txt). This treatment covered what was known up to 1956, but Rabinowitch admitted that the project was much larger than he anticipated and that by 1956 any attempt to comprehensively cover photosynthesis would be impossible in one or a few volumes. Govindjee joined Rabinowitch in publishing a general interest book to stimulate interest in photosynthesis (Rabinowitch and Govindjee 1969). But Govindjee wanted to put something in place that would chronicle the rapid advances being made in photosynthesis. Thus was born the series Advances in Photosynthesis. Over the years the title was expanded to Advances in Photosynthesis and Respiration and then, responding to the interest in photosynthesis as the source of biologically derived energy, Advances in Photosynthesis and Respiration-Including Bioenergy and Related Processes, a nod to the title of the Rabinowitch series Photosynthesis and Related Processes. From volume 1 (Bryant 1994), Govindjee's vision was to cover photosynthesis (quoting from the front matter of Volume 38)

"from physics to agronomy and medicine; from femtosecond processes through season-long production to evolutionary changes over the course of the history of the Earth; from the photophysics of light absorption, excitation energy transfer in the antenna to the reaction centers, where the highly-efficient primary conversion of light energy to charge separation occurs, through the electrochemistry of intermediate electron transfer, to the physiology of whole organisms and ecosystems; and from X-ray crystallography of proteins to the morphology of organelles and intact organisms." 
Govindjee has worked tirelessly on these volumes. Whenever an issue comes up Govindjee will respond sending emails from India or Heathrow airport as quickly as from his office in Illinois. Your email inbox is not safe anytime of the day or night, Govindjee will send ideas and comments at any hour.

Govindjee's contributions to the field of photosynthesis through his vision for a series of books on the recent advances in the field deserve the highest praise. His vision for a comprehensive chronicle of photosynthesis has had a lasting impact on our field.

\section{Dmitriy Shevela}

Department of Chemistry

Umeå University, Sweden

Although I have met Govindjee only twice in real life (the first time was in 2006 during his visit at the Max Planck Institute for Bioinorganic Chemistry (Muelheim an der Ruhr, Germany) where I was working on my PhD), I was very lucky to work with 'virtual' Govindjee via internet on two journal review articles and two book chapters. In all cases it was always fascinating and highly educational for me to work with Govindjee! Among many other things I was really impressed with his encyclopedic knowledge of all previous and current literature in photosynthesis research and with his writing abilities to describe any studies or phenomena in a very clear and easily readable style. I would like to mention Govindjee's amazing working abilities as well.... Very often working hard to meet submission deadlines, Govindjee worked during nights and was sending his version of the draft at around 3 or 4 a.m. (his local time)! It is, therefore, very hard for me to believe that we are going to celebrate his 80th birthday. I would like to wish him many years of excellent health, personal happiness and working activity, which has already inspired several generations of scientists to study photosynthesis.

[Shevela and Govindjee's publications are highly educational-beginning students in the field should not miss these excellent reviews. All of them deal mostly with PS II. They include: Shevela et al. (2012) and Govindjee and Shevela (2011) as well as the two chapters on oxygenic photosynthesis which are in two different books (Shevela et al. 2013a, b)... JJE-R.]

\section{Daya Prakash Sinha}

Indian Administrative Service, retired

Noida, India

\section{Govindjee, as I know him}

There is a saying in Sanskrit that says that "Kings are honored in their kingdom, but learned are honored in all countries of the world." This saying stands confirmed when I see Govindjee's students, scholars and distinguished scientists from various countries excited about his 80th birthday, and are celebrating it with love and enthusiasm. I feel honored to be a part of it.

I have known Govindjee (from the time he used "Govindji" as his name) for over sixty years now. We were class fellows in the 11th grade in K.P. (Kayastha Pathshala) Intermediate College at Allahabad. We lived in the same locality. So, sometimes we would go to the College together. In due course we became friends. Govindjee has often reminded me that I had a bicycle, while he did not have one. So we would go to the College 'doubling' on the bicycle; this means that I would be cycling, while he would sit on the carrier above the rear wheel.

Govindjee's father had passed away in 1943, when he was only 11 year old, but he was part of a very warm and affectionate family, headed by his elder brother Krishnaji (Professor of Physics). Govindjee used to address him as 'Dada' (elder brother in Hindi). So, I also called him 'Dada'. He was very pleasant and friendly. I never saw him raising his voice. Equally warm and friendly were other members of his family: Dada's wife, his mother, two younger brothers (Gopalji and Govindjee) and a sister (Malati) - all lived together in a joint family. I visited Govindjee quite frequently and became friendly with all the family members. On this occasion, I remember Govindjee's mother, who in her frail body was embodiment of motherly love.

Today with hindsight, I see that there are many things that are not common between us. Govindjee is one of the most organized persons I have seen. Against it, I am as disorganized as one can be. He had been focused and always knew what he wanted to do and achieve in life. In contrast, I was confused, studying science, while harboring a desire to be a writer and an actor, who ultimately settled for a sedate administrative job in the Indian government. I would not reply to Govindjee's letters promptly and not keep words with him. Yet we continued to remain friends for sixty-five years, or more, because of his large heartedness and capacity to overlook the frailties of friends.

When we were in college, Govindjee was not different from most of us. He participated in all our doings and misdoings like everyone else. We gossiped, went out for excursions and often aimlessly indulged in 'window shopping'. Govindjee was with us all the time.

I was directing a play for the Students Union of Allahabad University in which I was also acting. Even though Govindjee had no interest in theatre, he was there with me to help me as a friend. There was a scene in the play in which I was required to ask questions with my own self, and the reply thereto was to come from my inner-self. It was decided that my inner voice would be heard from off- 
stage. Govindjee was given the script and responsibility to speak the dialogues of my inner voice from off-stage. The play was rehearsed accordingly. But on the final day of performance, Govindjee failed to deliver the dialogues of my inner voice from off-stage. He had dropped the unnumbered pages of the script on the floor, and, thus, the text was messed up. I was nervous. I kept on repeating my dialogue in the hope that the next dialogue would be heard from the off-stage. But there was no response. The play suddenly came to a grinding halt. The audience came to know that the play had come apart. They started hooting, booing and whistling. I shouted-'Drop the Curtain'. The play was over. I rushed into the wings, seething with anger. But Govindjee was not there. He had vanished for fear of being scolded by me. However, after a few days, he came to see me and explained what had happened. I, of course, forgave him for this. Govindjee, sometimes, tells this story with relish.

We had founded a literary club named "Aaok", which met every Friday in a restaurant, or in the home of a friend (Amarnath Bhargava). We read papers on different subjects, held discussions on contemporary issues, and sometimes invited distinguished persons to speak to us. Govindjee's participation in "Aalok" was regular and enthusiastic. Most of us read papers or talked on subjects, not necessarily limited to the subjects we were pursuing in the University. But Govindjee invariably confined himself to subjects of study for his university degree. He was furiously focused on his academic studies. With his diverse activities, he would not allow his studies to be ignored. One of our mutual friends Mahesh Bharti who had lived at Govindjee's house for sometime told me that even on the days Govindjee would say that he was feeling unwell, he would sit on his study table for $4-5 \mathrm{~h}$ at a stretch. Not surprising, he topped in his BSc and MSc classes.

Today, while writing this, I look back at the life of Govindjee, and I am reminded of 'Arjun', a well-known character in the great Indian epic Mahabharat. Arjun and his brothers were learning archery from their Guru (the teacher) Drona. One day the Guru decided to test the skills of his disciples. He declared that one who would pierce the eye of the bird sitting on the tree would be declared winner. Accordingly, one of the disciples aimed his arrow at the eye of the bird. The Guru asked him does he see the bird? Does he see the feathers of the bird? Does he see the beak of the bird? The disciple replied in affirmative. Then he shot the arrow but missed the bird's eye. Similarly, all other disciples of the Guru, except Arjun, admitted seeing the bird, its feathers and its beak while aiming at its eye. They failed to hit the eye. At last, Arjun was summoned. When he aimed his arrow at the eye of the bird, the Guru asked him if he was seeing the bird. Arjun replied-'No'. Guru again asked him if he was seeing bird's feather or beak. Arjun replied-'No'. Guru asked him-'What do you see?' Arjun replied-'I see the bird's eye. Only the eye, and nothing else.' And when Arjun shot the arrow, it hit the bird's eye. Similarly Govindjee is focused on photosynthesis. He lives, breathes and talks photosynthesis. He has hit the bird's eye.

One cannot talk of Govindjee without mentioning Rajni. The two are inseparable, and probably 'made for each other', by some "Higher Power". We feel proud of them. Govindjee is not much different from all of us, but he has lived his life differently from all of us. As enjoined in holy Vedas, I pray that Govindjee may live for a hundred years, serving science and humanity.

\section{Alexandrina (Sandra) Stirbet \\ Retired Biophysicist \\ Newport News, VA}

The first time I met Govindjee was during his stay at JussyLullier, in Switzerland, when visiting Reto J. Strasser, with whom I was collaborating during 1993-2000. Govindjee became interested in my project regarding the simulation of the fast phase of chlorophyll $a$ fluorescence induction, and gave me much helpful information regarding PS II function, writing his comments on the blackboard, and explaining to me how several PS II components were supposed to influence the chlorophyll $a$ fluorescence. He also helped me by selecting the right references, by advising me how to organize the paper, and by editing it. Even when he was not there, I used to FAX him parts of the manuscript that we were writing, to ask for his advice. I vividly remember that once, by error, I called his home phone number instead of the fax and I woke him up in the middle of the night; I felt awful, but he mildly admonished me not to repeat that mistake. This was my first paper with him as co-author, which was published in the Journal of Theoretical Biology in 1998 (Stirbet et al. 1998). Then, I met Govindjee in person at the XIth International Photosynthesis Congress in Budapest, Hungary, where I had the privilege to introduce to him some of my Rumanian colleagues from the University of Bucharest, who were extremely impressed.

I left Switzerland for USA in 2000. In January 2010, to my surprise, I received an e-mail from Govindjee in which he wished me Happy New Year and asked me to write with him a paper in honor of Reto J. Strasser, who had retired. As I am not affiliated with any university or laboratory, he agreed to provide me with all the research papers necessary to work on the analysis of the OJIP fluorescence transient. It took us some time to put all the information together, but we succeeded in publishing this important paper in the Journal of Photochemistry and Photobiology (Stirbet and Govindjee 2011). Since we found our collaboration 
rewarding, we wrote a second review on chlorophyll $a$ fluorescence induction published in Photosynthesis Research (Stirbet and Govindjee 2012), and now, we continue to work on several of his ideas on other projects for future papers. He suggested even the subject of the paper (Connectivity in PSII) that I wrote for this special issue of Photosynthesis Research.

During these past few years of close interaction I realized how wonderful and compassionate a person Govindjee is, and how great and contagious is his passion for photosynthesis research. I consider myself extremely lucky to have the opportunity to acquire such a great mentor and good friend. However, collaborating with him is not always easy. He has high working standards, and is very demanding regarding the correctness and precision of all scientific ideas and language. Especially regarding the English language, Govindjee is very demanding, and as have many of his former foreign students and collaborators, I received from him the little book The Elements of Style by Strunk and White, and I am often reminded to perfect my English. In all this time, I have not met with him in person, our communication being limited to e-mails or phone calls. However, now, after 15 years, I finally met him during the 16th International Photosynthesis Congress in St. Louis. It was a fruitful although brief meeting.

\section{Colin Wraight}

Professor of Biochemistry, Biophysics and Plant Biology University of Illinois at Urbana-Champaign

Govindjee was already well known to me before I arrived at the University of Illinois at Urbana-Champaign, in 1975. $\mathrm{He}$ was not only well-respected for his extensive and seminal work on the Emerson enhancement effect and on chlorophyll fluorescence, but he was also a warm and immensely likeable "character", who was totally approachable by anyone interested in photosynthesis-a trait that has not diminished over the years. As a graduate student I was lucky enough to attend the first international photosynthesis congress, in Freudenstadt, in 1967, where Govindjee announced that he was taking Triton $\mathrm{X}$ as his first name.

When I came to Illinois, my lab was next door to Govindjee's, and was so for many years. The mentoring I received from my department was outstanding, but none more so than Govindjee's. Gov went out of his way to ensure that anything in his lab was available to me, if needed, and he constantly engaged me in discussions and analyses of his lab's work, as well as encouraging collaborations. The latter I largely eschewed, knowing that establishing my independence was essential to my career development, but I did work on one very enjoyable project with Gov's graduate student, Paul Jursinic.
All through my career, Gov has been a wonderful mentor, colleague and friend, and I can't really imagine how things might have been without his constant and nurturing presence. Even today, he continues to pay deep and meaningful attention to the well being of all his colleagues. My wife, Mary, and I consider ourselves very lucky to know Govindjee and his wife, Rajni, and to be among their friends.

[I would like to mention the outstanding papers Wraight and Govindjee have published together: Jursinic et al. (1978), Shopes et al. (1989), Wang et al. (1992), and Shinkarev et al. (1997)... JJE-R.]

\section{Concluding remarks}

Following these wonderful tributes it still remains to congratulate Govindjee on the many other honors he has received over the years. Just a few of them are mentioned

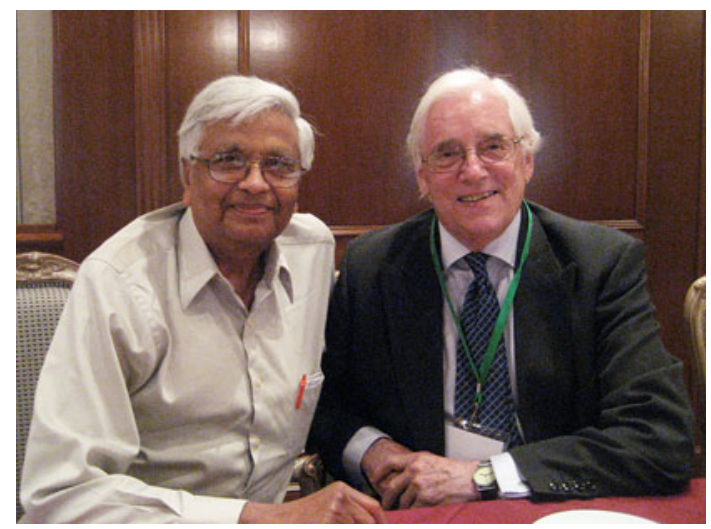

Fig. 6 Govindjee (left) with John Walker (Nobel Prize in Chemistry, 1997; http://www.mrc-mbu.cam.ac.uk/people/walker) at the 2013 conference on Photosynthesis and Sustainability, held in June, in Baku, Azerbaijan

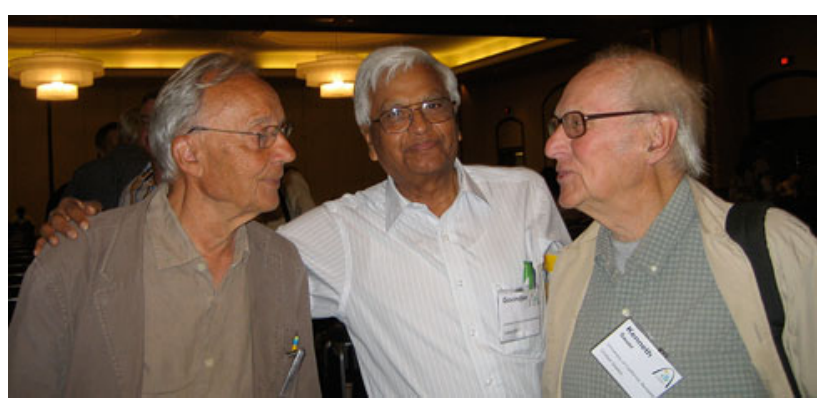

Fig. 7 Still enjoying science at $80^{+}$years. Pierre Joliot of France (left) Govindjee (center) and Ken Sauer of Berkeley, California (right). Photograph taken at the 16th International Congress on Photosynthesis in St. Louis, August 2013 


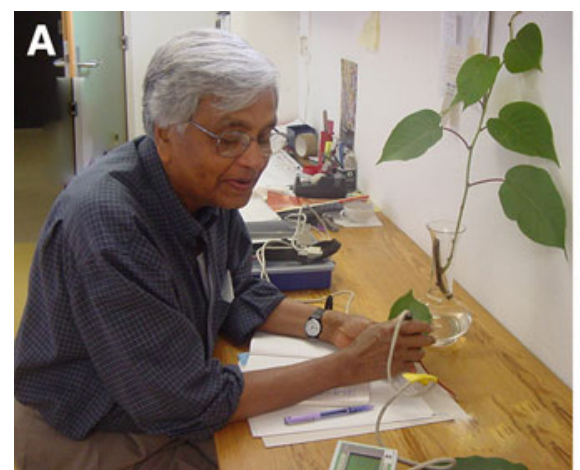

Fig. 8 Govindjee in action. Top Left: Making chlorophyll fluorescence measurements on a bean leaf in Reto Strasser's lab when the two proposed the OJIP nomenclature for fluorescence transient (Strasser and Govindjee 1991, 1992). Top Right: Govindjee at the experimental plot of corn (Zea mays), where Carl Bernacchi (at the University of Illinois at Urbana-Champaign) was making experiments

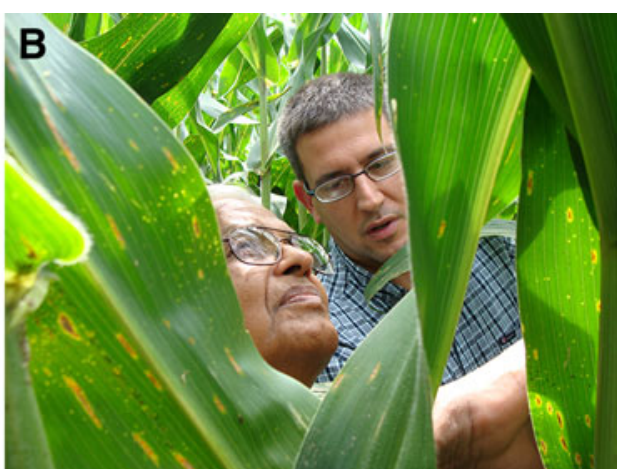

on the combined effect of increasing $\mathrm{CO}_{2}$ and higher temperatures. These pictures are from a pdf file available originally from a "News Letter" of the School of Integrative Biology at the University of Illinois at Urbana-Champaign entitled "Govindjee, Mr. Photosynthesis" (however, it is also available at: http://xa.yimg.com/kq/groups/ 15186538/90763443/name/Govindjee+seminar+Abstract.pdf) here: Fellow of the American Association for the Advancement of Science (1976); Fellow and life member of the National Academy of Science of India (1978); President of the American Society of Photobiology (1980-1981); the very first Lifetime Achievement Award of the Rebeiz Foundation for Excellence in Biological Sciences (2006); the prestigious Communication Award of the International Society of Photosynthesis Research (2007); and to him the most pleasant is from his home: Lifetime Achievement Alumni Award of the College of Liberal Arts and Sciences, of the University of Illinois at Urbana-Champaign (2008). In addition, the University of Indore, in India, held an international symposium in 2008.

Finally, we end this Tribute by showing photographs that celebrate his life in different ways. We know that he loves to take photographs and enjoys them. We have already shown Figs. 2, 3, 4 and 5, Fig. 2 showed his photographs with the 2013 Awardees of the Govindjee and Rajni Govindjee Awards for Excellence in Biological Sciences. Figures 3, 4 and 5 showed his photographs with some of the many others he enjoys being with-both at home and on his travels, Govindjee cherishes having conversations with many scientists from those starting out on their careers to Nobel laureates. Figure 6 shows a 2013 photograph with John Walker (Nobel laureate in Chemistry, 1997). Figure 7 shows a photograph, taken at the 16th International Photosynthesis Congress, August, 2013, with two of the scientists who are also $80^{+}$and who Govindjee admires for their research and discoveries: Pierre Joliot of France and Ken Sauer of Berkeley, California. Finally, Fig. 8 shows what he enjoys most: looking and working with plants-both in the lab and outdoors. Happy 80th to you Gov from all your photosynthesis friends and colleagues around the World and I'm sure we are joined by all you have touched with your warm humanity in many other walks of life ${ }^{3}$.

Acknowledgments I am very thankful to all (almost 40) who sent me their write-ups on Govindjee, ranging from his personal life to his scientific achievements. Special thanks go to Rajeshwari Pandharipande for the appropriate "Shloka". We thank Rajni Govindjee for taking many of the photographs shown in this Tribute, Karl Schlipf (UIUC, Urbana, IL) for preparing the final copy of Fig. 1C, Joan Huber (UIUC, Urbana, IL) for the photographs in Fig. 2 (see photographs by Joan Huber, taken in 2012, and earlier years at: http://www. life.illinois.edu/govindjee/photooftheyear2012.html), Reto Strasser (of Geneva, Switzerland) for Fig. 8A, and Andy VanLoocke (UIUC, Urbana, IL) for Fig. 8B. Finally, we thank Sandra Stirbet for helping me check the proofs.

\section{Appendix 1}

An alphabetical, perhaps incomplete, list of co-authors and co-editors of Govindjee

Abilov, Z.K.; Abrol, Yash Pal; Adamec, F.; Alia, A.; Aligizaki-Zorba, Aikaterni; Allakhverdiev, Suleyman I.; Allen, John F.; Amesz, Jan; Ananyev, Genady M.; Anton, John; Armond, Paul; Arnold, William A.; Aro, Eva-Mari;

\footnotetext{
${ }^{3}$ Interestingly, and very appropriately, two educational videos "Photosynthesis Part I: The Light Dependent Reactions, and Photosynthesis Part II, The Calvin [-Benson] Cycle" are planned to be dedicated to Govindjee by Janet L. McDonald, MS, RD (USA). Janet is a Registered Dietitian, a Science Educator and the Author, Creator and Producer of BIOL-O-GEE R.A.P. TM educational science videos. In addition, she plans to dedicate to Gov the "Photosynthesis Study Guides" that will go along with the videos. She wrote the following message for Gov at the time of the page proofs of my article:

"YOU, Govindjee, are the gift.....to students, to educators, to people and to all creation. I am honored more than words can say to dedicate this work to you. Thank you so much, Janet"... JJE-R.
} 
Astier, Chantal; Augur, Julie; Britt, R.D.; Babcock, Gerald T.; Babin, M.; Baianu, Ion C.; Baker, Neil; Barber, James (Jim); Bazzaz (Bakri), Maarib; Beatty, J. Thomas (Tom); Bedell, Glenn Wesley II; Berkowitz, Gerald A.; Bharti, Sudhakar; Biswal, A.K.; Björn, Lars Olof; Black, Clanton C., Blair, L.C.; Blankenship, Robert E. (Bob); Blubaugh, Danny J.; Bohnert, Hans; Bosa, Karolina; Bose, Salil; Bottomley, W.; Boyer, John S.; Brezina, F.; Briantais, Jean-Marie; Britt, David; Bryant, Donald A.; Caliandro, R.; Chen, S.; Chen Y.-C.; Cullen, J.J.; Cao, Jiancheng; Cederstrand, Carl Nelson; Cho, Frederick Yi-Tung (Fred); Chollet, Raymond (Ray); Chow, W.-S.. (Fred); Clegg, Robert M. (Bob); Cohen, Martin; Coleman, William Joseph (Bill); Cramer, William A. (Bill); Crespi, Henry L.; Crisp, David; Critchley, Christa; Crofts, Antony R. (Tony); Daniell, Henry; Das, Mrinmoyee; De Klerk, Hank; de Vos, Oscar; Debrunner, Peter G.; Decampo, R.; Demeter, Sandor; Desai, T.S.; DeSturler, E.; DeVault, Don; Dilley, Richard A (Dick); Döring, G.; Downie, Steve; Downton, W.J.S.; Dravins D.; Ducruet, Jean-Marc; Duysens, L.N.M. (Lou); Eaton-Rye, Julian John; Edwards, Gerald E. (Gerry); Eggenberg, Peter; Eichacker, L.A.; El-Shintinawy, Fatma; Etienne, Ann-Lise; Fenton, James M. (Jim); Finkele, U.; Fleischman, D.; Fork, David C. (Dave); Foyer, Christine; Freyssinet, Georges; Funk, Christiane; Garab, Gyözö; García-Mendoza, Ernesto; Gasanov, Ralph; Gazanchyan, R.M.; Gest, Howard; Ghosh, Ashish K.; Gilmore, Adam M.; Gnanam, A.; Goedheer, J.H.C. (Joop); Gohlke, C.; Goldstein, C.; Goltsev, Vasilej; Gorham, H.H.; Govindjee (Varma), Rajni; Grantz, David; Gratton, Enrico; Greenfield, Scott; Gross, Elizabeth L.; Gunning, Brian; Gutowsky, Herbert S.; Hagar, W.; Haghighi, B.; Halls, S.; Hammond, J.H.; Hartman, S.R.; Haselkorn, Robert; Hazlett, Theodore L. (Chip); Heiss, G.J.; Hendrickson, David N.; Hirsch, R.E.; Hirschberg, J.; Hoch, George; Hoff, Arnold J.; Holub, Oliver (Olli); Homann, Peter H.; Hope, A.B.; Hou, C.; Huseynova, I. M.; Hutchison, Ron; Ichimura, Shoji; Inoue, Yorinao; Irrgang, K.-D.; Itoh, Shigeru; Jacobsen-Mispagel, K; Jajoo, Anjana; Johnson, Douglas G.; Jordan, Doug; Junge, Wolfgang; Jursinic, Paul A.; Kumar, D.; Kambara, Takeshi; Kamen, Martin D.; Kalaji, H.M.; Kana, Radek; Katz, Joseph J. (Joe); Kaufmann, Kenneth (Ken); Keranen, M.; Kern, Jan F.; Keresztes, Aron; Khanna, Rita; Kiang, Nancy Y.; Kirilovsky, Diana; Knaff, David; Knox, Robert (Bob); Koenig, Friederike; Koike, H.; Kolling, D.R.J.; Komárek, O.; Koscielniak, J.; Kotabová E.; Kramer, David; Krey, Anne; Krogmann, David; Kumar, D.; Kurbanova, U.M.; Laisk, Agu; Laloraya, Manmohan M.; Lauterwasse, C.; Lavorel, Jean; Leelavathi, S.; Li, H.; Li, K.-B.; Li, Rong; Lin, C.; Lin, R.N.; Loach, Paul A.; Long, Steven P. (Steve); Maenpaa, Pirko; Malkin, Shmuel; Mar, Ted; Marcelle, R.; Marchesini, N.; Markley, John L.; Marks, Stephen B.; Maróti,
Peter; Matsubara, Shizue; Mathis, Paul; Mayne, L.; McCain, Douglas C.; McTavish, H.; Meadows, Victoria S.; Merkelo, Henri; Messinger, Johannes; Mimuro, Mamoru; Minagawa, Jun; Miranda, T.; Moghaddam, A.N., Mohanty, Prasanna [Kumar]; Moore, Gary; Moya, Ismael; Mullet, John E.; Mulo, P.; Munday, John Clingman, Jr. (John); Murata, Norio; Murty, Neti R. (Murty); Naber, D.; Nakatani, Herbert Y. (Herb); Najafpour, M.M. (Mahdi); Nedbal, Ladislav (Lada); Nickelsen, Karin; Nozzolillo, C.G.; Ocampo-Alvarez, H.; Oesterhelt, Dieter; Ogawa, Teruo; Ogren, William L. (Bill); Ohad, N.; Oja, V.; O'Neil, Michael P.; Orr, Larry; Ort, Donald R. (Don); Owens, Olga.v.H.; Padhye, Subhash; Padden, Sean; Pandey, S.S.; Pareek, Ashwani; Pattanayak, Gopal K., Pishchalinikov, R.; Pakrasi, Himadri; Patil, S.C.; Paolillo, Dominick J.; Papageorgiou, George Christos (George); Pellin, M.J.; Peteri, Brigitta; Peters, W.R.; Pfister, Klaus; Picorel, R.; Porra, Robert J. (Bob); Portis, Archie R.; Prášil, Ondrej; Preston, Christopher; Prézelin, Barbara B.; Pulles, M.P.J. (Tini); Punnett, H.; Punnett, L.; Qiang, S.; Rabinowitch, Eugene, I, Rajan, S. (Rajan); Rajarao, T. (Rajarao); Rajwanshi, R.; Ranjan, Shri; Rebeiz, Constantin A. (Tino); Reddy, V.S.; Renger, Gernot; Rich, M.; Robinson, Howard H. (Howie); Rochaix, Jean-David; Roffey, Robin; Rogers, S.M.D.; Romijn, J.C.; Rose, Stuart; Roy, Guy; Royer, Cathy; Rozsa, Zs.; Ruan, Kangcheng; Ruiz, F.A.; Rupassara, S. Indumathi (Indu); Rutherford, A. William (Bill); Sane, Prafullachandra Vishnu (Raj); Saphon, Satham; Sarin, Neera Bhalla; Sarojini, G. (Sarojini); Satoh, Kazuhiko; Satoh, Kimiyuki; Savikhin, S.; Sayre, Richard (Dick); Schansker, Gert; Schideman, Lance C.; Schmidt, Paul G.; Schooley, Ralph E.; Schwartz, Beatrix (Trixie); Šedivá, B.; Segura, Antígona; Seibert, Michael (Mike); Selig, Ted C.; Sener, Melih; Sestak, Zdenek; Seuffereheld, Manfredo J.; Sharkey, Thomas D. (Tom); Shen, Jian-Ren; Shen, Yunkang; Sherman, Louis (Lou); Shevela, D.; Shim, Hyunsuk; Shimony, Carmela; Shinkarev, Vladimir P. (Vlad); Shopes, Robert (Bob); Siefert, Janet; Siggel, Ulrich (Uli); Singh, A.; Singhal, Gauri S.; Smith, William R., Jr.; Snel, J.F.H. (Jan); Sommerville, Chris. R.; Song, H.-Y.; Sopory, Sudhir K.; Spalding, Martin H. (Marty); Spencer, Jobie D.; Spilotro, Paul; Srivastava, Alaka; Srivastava, Shyam Lal; Stacey, W.T.; Stamatakis, Constantin (Kostas); Steinback, Katherine E.; Stemler, Alan James (Al); Stilz, H.U.; Stirbet, Alexandrina (Sandra); Strasser, Bruno; Strasser, Reto J.; Stys, D.; Subramaniam, Shankar; Suggett, J.; Svensson, Bengt; Sweeney, Beatrice M. (Beazy); Swenberg, C.E.; Szalay, Laszlo; Taoka, Shinichi (Shin); Tabrizi, M.A.; Tatake, V.G.; Telfer, Alison; Teramura, A.H.; Thomas, Jan B.; Thornber, J.Philip (Phil); Tinetti, Giovanna; Toon, Stephen; Török, M.; Tripathy, Baishnab C.; TsimilliMichael, Merope; Turpin, David H.; Tyagi, Vijay; Tyystjärvi, Esa; Tyystärvi, Tina; Vacek, Karl; Van de Ven, 
Martin; Van Gorkom, Hans; Van Rensen, Jack J.S.; VanderMeulen, David Lee (David); Vass, Imre; Vermaas, Willem F.J. (Wim); Vernotte, Claudie; Wagner, R.; Wang, Q.J. (Polly); Wang, Xutong; Warden, Joseph (Joe) T.; Wasielewski, Michael R. (Mike); Wattal, P.N.; Weger, H.G.; Whitmarsh, John C.; Widholm, J.M. (Jack); Wiederrecht, Gary P.; Wong, Daniel; Wraight, Colin A.; Wydrzynski, Thomas John (Tom); Xiong, Jin; Xu, Chunhe; Yin, C.; Yang, C.; Yang (Ni), Louisa; Yoo, Hyungshim; Younis, Hassan M.; Yu, H.; Yu, X.; Yu, Yong; Yusuf, M.A.; Zeng, X.-H.; Zhou, Yan; Zhu, Xinguang; Zhu, Yong; Zilinskas (Braun), Barbara Ann (Barbara); Zinth, W.; Zuk-Golaszewska, K.; and Zumbulyadis, Nick.

*Names of Govindjee's professors are bolded; those that we know are no more with us are in italics; for any errors in the list, please send an e-mail to Govindjee (gov@illinois.edu) since the list was prepared from information on his web site.

\section{Appendix 2}

The Special Issue celebrating Govindjee's 50 Years in Photosynthesis Research and his 75th Birthday, edited by Julian Eaton-Rye, was published in 2 parts:

[1] Part A was Volume 93, Issue 1-3, July 2007 (ISSN: 0166-8595 (Print) 1573-5079 (Online)); it had 22 articles

[2] Part B was Volume 94, Issue 2-3, November 2007 (ISSN: 0166-8595 (Print) 1573-5079 (Online)); it had 25 articles.

Together both volumes had a total of 47 articles (original papers and reviews), and 123 authors.

We honor here all the authors by listing their papers, alphabetically arranged by the first authors.

*We mourn the loss of those who left us since the publication of this special issue: Elizabeth Gross (1940-2007); Alex Hope (1928-2008); Prasanna Mohanty (1934-2013), and Gernot Renger (1937-2013).

Adams WW III, Watson AM, Mueh KE (2007) Photosynthetic acclimation in the context of structural constraints to carbon export from leaves. Photosynth Res 94:455-466

Bishop CL, Ulas S, Baena-Gonzalez E, Aro E-M (2007) The PsbZ subunit of Photosystem II in Synechocystis sp. PCC 6803 modulates electron flow through the photosynthetic electron transfer chain. Photosynth Res 93:139-147

Blankenship RE (2007) 2007 Awards of the International Society of Photosynthesis Research (ISPR). Photosynth Res 94:179-181

Castelfranco PA, Lu Y-K, Stemler AJ (2007) Hypothesis: the peroxydicarbonic acid cycle in photosynthetic oxygen evolution. Photosynth Res 94:235-246

Cavender-Bares J (2007) Chilling and freezing stress in live oaks (Quercus section Virentes): Intra and inter- specific variation in PSII sensitivity corresponds to latitude origin. Photosynth Res 94:437-453

Ducruet J-M, Peeva V, Havaux M (2007) Chlorophyll thermofluorescence and thermoluminescence as complementary tools for the study of temperature stress in plants. Photosynth Res 93:159-171

Eaton-Rye JJ (2007a) Celebrating Govindjee's 50 years in photosynthesis research and his 75th birthday. Photosynth Res 93:1-5

Eaton-Rye JJ (2007b) Snapshots of the Govindjee lab from the late 1960s to the late 1990s, and beyond... Photosynth Res 94:153-178

Fan D-Y, Nie Q, *Hope AB, Hillier W (2007) Quantification of cyclic electron flow around Photosystem I in spinach leaves during photosynthetic induction. Photosynth Res 94:347-357

Govindachary S, Bigras C, Harnois J (2007) Changes in the mode of electron flow to Photosystem I following chilling-induced photoinhibition in a C3 plant, Cucumis sativus L. Photosynth Res 94:333-345

Grennan AK, Ort DR (2007) Cool temperatures interfere with $\mathrm{D} 1$ synthesis in tomato by causing ribosomal pausing. Photosynth Res 94:375-385

*Gross EL (2007) A Brownian dynamics computational study of the interaction of spinach plastocyanin with turnip cytochrome $f$ : the importance of plastocyanin conformational changes. Photosynth Res 94:411-422

Guruprasad K, Bhattacharjee S, Kataria S (2007) Growth enhancement of soybean (Glycine max) upon exclusion of UV-B and UV-B/A components of solar radiation: characterization of photosynthetic parameters in leaves. Photosynth Res 94:299-306

Hoober JK, Eggink LL, Chen M (2007) Chlorophylls, ligands and assembly of light-harvesting complexes in chloroplasts. Photosynth Res 94:387-400

Iwai M, Kato N, Minagawa J (2007) Distinct physiological responses to a high light and low $\mathrm{CO}_{2}$ environment revealed by fluorescence quenching in photoautotrophically grown Chlamydomonas reinhardtti. Photosynth Res 94:307-314

Kern J, *Renger G (2007) Photosystem II: Structure and mechanism of the water: plastoquinone oxidoreductase. Photosynth Res 94:179-202

Kim E-H, Razeghifard R, Anderson JM, Chow WS (2007) Multiple sites of retardation of electron transfer in Photosystem II after hydrolysis of phosphatidylglycerol. Photosynth Res 93:149-158

Kirilovsky D (2007) Photoprotection in cyanobacteria: the orange carotenoid protein (OCP)-related non-photochemical-quenching mechanism. Photosynth Res 93:7-16

Koike H, Ikeda Y, Yusa F, Kashino Y (2007) Isolation and characterization of outer and inner envelope membranes of cyanelles from a glaucocystophyte, Cyanophora paradoxa. Photosynth Res 93:45-53 
Krogmann DW, Pérez-Gómez B (2007) The multidomain linkers determines the bundle-shape structure of the phycobilisome of the cyanobacterium Gloeobacter violaceus PCC 7421. Photosynth Res 93:27-43

Lambrev PH, Tsonev T, Velikova V (2007) Trapping of the quenched conformation associated with non-photochemical quenching of chlorophyll fluorescence at low temperature. Photosynth Res 94:321-332

Lichtenthaler HK, Babani F, Langsdorf G (2007) Chlorophyll fluorescence imaging of photosynthetic activity in sun and shade leaves of trees. Photosynth Res 93:235-244

Marin-Navarro J, Manuell AL, Wu J (2007) Chloroplast translation regulation. Photosynth Res 94:359-374

*Mohanty P, Allakhverdiev S, Murata N (2007) Application of low temperatures during photoinhibition allows characterization of individual steps in photodamage and the repair of photosystem II. Photosynth Res 94:217-224

Mohapatra A, Tripathy BC (2007) Differential distribution of chlorophyll biosynthetic intermediates in stroma, envelope and thylakoid membranes in Beta vulgaris. Photosynth Res 94:401-410

Nagata T, Nagasawa T, Zharmukhamedov SK (2007) Reconstitution of the water-oxidizing complex in manganese-depleted photosystem II preparations using synthetic binuclear $\mathrm{Mn}(\mathrm{II})$ and $\mathrm{Mn}(\mathrm{IV})$ complexes: production of hydrogen peroxide. Photosynth Res 93:133-138

Nedbal L, Cerveny J, Rascher U, Schmidt H (2007) E-photosynthesis: a comprehensive approach to understand chlorophyll transients and other complex dynamic features of photosynthesis in fluctuating light. Photosynth Res 93:223-234

Ogawa T, Mi H (2007) Cyanobacterial NADPH dehydrogenase complexes. Photosynth Res 93:69-77

Papageorgiou GC, Tsimilli-Michael M (2007) The fast and slow kinetics of chlorophyll $a$ fluorescence induction in plants, algae and cyanobacteria: a viewpoint. Photosynth Res 94:275-290

Pfundel EF, Ghozlen NM, Meyer S (2007) Investigating UV screening in leaves by two different types of portable UV fluorimeters reveals in vivo screening by anthocyanins and carotenoids. Photosynth Res 93:205-221

Popelkova H, Yocum CF (2007) Current status of the role of $\mathrm{Cl}^{-}$ion in the oxygen-evolving complex. Photosynth Res 93:111-121

Roberts K, Granum E, Leegood RC, Raven JA (2007) Carbon acquisition by diatoms. Photosynth Res 93:79-88

Satoh K, Yamamoto Y (2007) The carboxyl-terminal processing of precursor D1 protein of the photosystem II reaction center. Photosynth Res 94:203-215
Shevela D, Klimov V, Messinger J (2007) Interactions of photosystem II with bicarbonate, formate and acetate. Photosynth Res 94:247-264

Singh AK, Sherman LA (2007) Reflections on the function of Isi, a cyanobacterial stress-inducible, Chlbinding protein. Photosynth Res 93:17-25

Sugita C, Ogata K, Shikata M (2007) Complete nucleotide sequence of the freshwater unicellular cyanobacterium Synechococcus elongatus PCC 6301 chromosome: gene content and organization. Photosynth Res 93:55-67

Summerfield TC, Eaton-Rye JJ, Sherman LA (2007) Global gene expression of a $\Delta$ PsbO: $\Delta$ PsbU mutant and a spontaneous revertant in the cyanobacterium Synechocystis sp. strain PCC 6803. Photosynth Res 94:265-274

Suorsa M, Aro E-M (2007) Expression, assembly and auxiliary functions of photosystem II oxygen-evolving proteins in higher plants. Photosynth Res 93:89-100

Sveshnikov D, Funk C, Schroder W (2007) The PsbPlike protein (sll11418) of Synechocystis sp. PCC stabilises the donor side of Photosystem II. Photosynth Res 93:101-109

Thach LB, Shapcott A, Schmidt S (2007) The OJIP fast fluorescence rise characterizes Graptophyllum species and their stress responses. Photosynth Res 94:423-436

Tiwari A, Jajoo A, Bharti S, *Mohanty P (2007) Differential response of chloride binding sites to elevated temperature: a comparative study in spinach thylakoids and PSII-enriched membranes. Photosynth Res 93:123-132

Toth SZ, Schansker G, Strasser RJ (2007) A non-invasive assay of the plastoquinone pool redox state based on the OJIP-transient. Photosynth Res 93:193-203

Van der Weij-de Wit CD, Ihalainen JA, Van Grondelle R (2007) Excitation energy transfer in native and unstacked thylakoid membranes studied by low temperature and ultrafast fluorescence spectroscopy. Photosynth Res 93:173-182

Van Rensen JJS, Vredenberg WJ, Rodrigues GC (2007) Time sequence of the damage to the acceptor and donor sides of photosystem II by UV-B radiation as evaluated by chlorophyll $a$ fluorescence. Photosynth Res 94:291-297

Vredenberg W, Durchan M, Prasil O (2007) On the chlorophyll $a$ fluorescence yield in chloroplasts upon excitation with twin turnover flashes (TTF) and high frequency flash trains. Photosynth Res 93:183-192

Wydrzynski T, Hillier W, Conlan B (2007) Engineering model proteins for Photosystem II function. Photosynth Res 94:225-233

Zhang R, Li H, Xie J, Zhao J (2007) Estimation of relative contribution of "mobile phycobilisome" and "energy spillover" in the light-dark induced state transition in Spirulina platensis. Photosynth Res 94:315-320 


\section{References}

Allakhverdiev SI, Huseynova IM, Govindjee (2012) International conference on "Photosynthesis research for sustainability2011", July 24-30, 2011, Baku, Azerbaijan. Photosynth Res 110:205-212

Allakhverdiev SI, Huseynova IM, Govindjee (2013) International conference on "Photosynthesis research for sustainability-2013: in honor of Jalal A. Aliyev", held during June 5-9, 2013, Baku, Azerbaijan. Photosynth Res. doi:10.1007/s11120-013-9901-7

Arnold WA, Sherwood HK (1957) Are chloroplasts semiconductors? Proc Natl Acad Sci USA 43:105-114

Baianu IC, Critchley C, Govindjee, Gutowsky HS (1984) NMR study of chloride-ion interactions with thylakoid membranes. Proc Natl Acad Sci USA 81:3713-3717

Bawden FC (1943) Plant viruses and virus diseases. Chronica Botanica, Waltham

Bazzaz MB, Govindjee (1973) Photochemical properties of mesophyll and bundle sheath chloroplasts of maize. Plant Physiol 52:257-262

Bazzaz MB, Paolillo DJ, Govindjee (1974) Biochemical, spectral and structural study of olive necrotic 8147 mutant in Zea mays L. Z Pflanzenphysiol 72:181-192

Bedell G, Govindjee (1966) Quantum yield of oxygen evolution and the Emerson enhancement effect in deuterated Chlorella. Science 152:1383-1385

Bedell GW, Govindjee (1973) Photophosphorylation in intact algae: effects of inhibitors, intensity of light, electron acceptors and donors. Plant Cell Physiol 14:1081-1097

Björn LO, Govindjee (2009) The evolution of photosynthesis and chloroplasts. Curr Sci (India) 96:1466-1474

Björn LO, Papageorgiou GC, Blankenship R, Govindjee (2009a) A viewpoint: why chlorophyll $a$ ? Photosynth Res 99:85-98

Björn LO, Papageorgiou GC, Dravins D, Govindjee (2009b) Detectability of life and photosynthesis on exoplanets. Curr Sci (India) 96:1171-1175

Brody SS (2002) Fluorescence lifetime, yield, energy transfer and spectrum in photosynthesis, 1950-1960. Photosynth Res 73:127-132

Bryant DA (ed) (1994) The molecular biology of cyanobacteria. Advances in photosynthesis, vol 1. Kluwer, The Hague

Cederstrand C, Govindjee (1961) Some properties of spinach chloroplast fractions obtained by digitonin solubilization. Biochim Biophys Acta 120:177-180

Cederstrand C, Rabinowitch E, Govindjee (1966a) Absorption and fluorescence spectra of spinach chloroplast fractions obtained by solvent extraction. Biochim Biophys Acta 120:247-258

Cederstrand C, Rabinowitch E, Govindjee (1966b) Analysis of the red absorption band of chlorophyll $a$ in vivo. Biochim Biophys Acta 126:1-12

Cho F, Govindjee (1970a) Low-temperature (4-77 K) spectroscopy of Chlorella: temperature dependence of energy transfer efficiency. Biochim Biophys Acta 216:139-150

Cho F, Govindjee (1970b) Low temperature (4-77 K) spectroscopy of Anacystis: temperature dependence of energy transfer efficiency. Biochim Biophys Acta 216:151-161

Chow WS, Funk C, Hope AB, Govindjee (2000) Greening of intermittent light-grown bean plants in continuous light: thylakoid components in relation to photosynthetic performance and capacity for photoprotection. Ind $\mathbf{J}$ Biochem Biophys 37: 395-404 [Special Issue on "Photosynthesis", organized by Prasanna Mohanty and Parag Chitnis]

Clegg RM (2012) Contributions of Govindjee, 2000-2011. In: EatonRye JJ, Tripathy BC, Sharkey TD (eds) Photosynthesis: plastid biology, energy conversion and carbon assimilation, Advances in photosynthesis and respiration, vol 34. Springer, Dordrecht pp 835-844

Commoner B, Nehari V (1953) The effects of tobacco mosaic virus synthesis on the free amino acid and amide composition of the host. J Gen Physiol 36:79-80

Das M, Govindjee (1967) A long-wave absorbing form of chlorophyll $a$ responsible for the red drop in fluorescence at $298 \mathrm{~K}$ and the F723 band at $77 \mathrm{~K}$. Biochim Biophys Acta 143:570-576

Demmig-Adams B, Garab G, Adams W III, Govindjee (eds) (2014) Non-photochemical quenching and energy dissipation in plants, algae and cyanobacteria. Advances in photosynthesis and respiration including bioenergy and related processes. Springer, Dordrecht (in press)

DeVault D, Govindjee (1990) Photosynthetic glow peaks and their relationship with the free energy changes. Photosynth Res 24:175-181

DeVault D, Govindjee, Arnold W (1983) Energetics of photosynthetic glow peaks. Proc Natl Acad Sci USA 80:983-987

Duysens LNM (1952) Transfer of excitation energy in photosynthesis. Doctoral Thesis, State University Utrecht, The Netherlands

Eaton-Rye JJ (2007a) Celebrating Govindjee's 50 years in photosynthesis research and his 75th birthday. Photosynth Res 93:1-5

Eaton-Rye JJ (2007b) Snapshots of the Govindjee lab from the late 1960s to the late 1990s, and beyond... Photosynth Res 94: $153-178$

Eaton-Rye JJ (2012) Contributions of Govindjee, 2000-2011. In: Eaton-Rye JJ, Tripathy BC, Sharkey TD (eds) Photosynthesis: plastid biology, energy conversion and carbon assimilation, Advances in photosynthesis and respiration, vol 34. Springer, Dordrecht, pp 815-834

Eaton-Rye JJ, Govindjee (1988a) Electron transfer through the quinone acceptor complex of Photosystem II in bicarbonate-depleted spinach thylakoid membranes as a function of actinic flash number and frequency. Biochim Biophys Acta 935:237-247

Eaton-Rye JJ, Govindjee (1988b) Electron transfer through the quinone acceptor complex of Photosystem II after one or two actinic flashes in bicarbonate-depleted spinach thylakoid membranes. Biochim Biophys Acta 935:248-257

Emerson R, Chalmers RV (1958) Speculations concerning the function and phylogenetic significance of the accessory pigments of algae. Phycol Soc News Bull 11:51-56

Emerson R, Chalmers RV, Cederstrand CN (1957) Some factors influencing the longwave limit of photosynthesis. Proc Natl Acad Sci USA 43:133-143

Fenton JM, Pellin MJ, Kaufmann K, Govindjee (1979) Primary photochemistry of the reaction center of Photosystem I. FEBS Lett 100:1-4

Garab G, Rozsa Z, Govindjee (1988) Carbon dioxide affects charge accumulation in leaves: measurements by thermoluminescence. Naturwiisenschaften 75:517-519

Ghosh AK (2004) Passage of a young Indian physical chemist through the world of photosynthesis research in Urbana, Illinois, in the 1960s: a personal essay. Photosynth Res 80:427-437

Gilmore AM, Hazlett TL, Govindjee (1995) Xanthophyll cycledependent quenching of Photosystem II chlorophyll $a$ fluorescence: formation of a quenching complex with a short fluorescence lifetime. Proc Natl Acad Sci USA 92:2273-2277

Gilmore AM, Shinkarev VP, Hazlett TL, Govindjee (1998) Quantitative analysis of the effects of intrathylakoid $\mathrm{pH}$ and the xanthophyll cycle pigments on chlorophyll $a$ fluorescence lifetime distributions and intensity in thylakoids. Biochemistry 37:13582-13593

Govindjee (1995) Sixty-three years since Kautsky: chlorophyll $a$ fluorescence. Aust J Plant Physiol (now Funct Plant Biol) 22:131-160 
Govindjee (1999) On the requirement of minimum number of four versus eight quanta of light for the evolution of one molecule of oxygen in photosynthesis: a historical note. Photosynth Res 59:249-254

Govindjee (2004) Chlorophyll $a$ fluorescence: a bit of basics and history. In: Papageorgiou GC, Govindjee (eds) Chlorophyll $a$ fluorescence: a signature of photosynthesis. Advances in photosynthesis and respiration, vol 19. Springer, Dordrecht, pp 1-42

Govindjee (2008) Recollections of Thomas John Wydrzynski. Photosynth Res 98:13-31

Govindjee (2010) Celebrating Andrew Alm Benson's 93rd birthday. Photosynth Res 105:201-208

Govindjee, Barber J (1980) Photosynthesis session of the British Photobiology Society meeting. Photobiochem Photobiophys 1:183-187

Govindjee, Björn LO (2012) Dissecting oxygenic photosynthesis: the evolution of the "Z"-scheme for thylakoid reactions. In: Itoh S, Mohanty P, Guruprasad KN (eds) Photosynthesis: overviews on recent progress and future perspectives. IK Publishers, New Delhi, pp 1-27

Govindjee, Briantais JM (1972) Chlorophyll $b$ fluorescence and an emission band at $700 \mathrm{~nm}$ at room temperature in green algae. FEBS Lett 19:278-280

Govindjee, Fork DC (2006) Charles Stacy French (1907-1995) biographical memoirs, vol 88. National Academy of Sciences, Washington, DC, pp 2-29

Govindjee, Govindjee R (1974) Primary events in photosynthesis. Sci Am 231:68-82

Govindjee, Jursinic PA (1979) Photosynthesis and fast changes in light emission by green plants. Photochem Photobiol Rev 4:125-205

Govindjee, Knaff D (2006) Editorial: international photosynthesis congresses (1968-2007). Photosynth Res 89:1-2

Govindjee, Rabinowitch E (1960) Two forms of chlorophyll $a$ in vivo with distinct photochemical function. Science 132:355-356

Govindjee, Seibert M (2010) Picosecond spectroscopy of the isolated reaction centers from the photosystems of oxygenic photosynthesis-ten years (1987-1997) fun. A tribute to Micheal R. Wasielewski on his 60th birthday. Photosynth Res 103:1-6

Govindjee, Shevela D (2011) Adventures with cyanobacteria: a personal perspective. Front Plant Sci 2:28. doi:10.3389/fpls. 2011.00028

Govindjee, Srivastava SL (eds) (2010) A tribute to Professor Krishnaji. Printed at Apex Graphics, Allahabad, 266 pp. (its pdf file is available free at: http://www.life.illinois.edu/govindjee/recent_ papers.html)

Govindjee, Yoo H (2007) The international society of photosynthesis research (ISPR) and its associated international congress on photosynthesis (ICP): a pictorial report. Photosynth Res 91:95-106

Govindjee, Laloraya MM, Rajarao T (1956) Formation of asparagine and increase in the free amino acid content in virus infected leaves of Abelmoschus esculentus. Experientia 12:180-181

Govindjee, Rabinowitch E, Thomas JB (1960a) Inhibition of photosynthesis in some algae by extreme red light. Biophys J 1:91-97

Govindjee R, Thomas JB, Rabinowitch E (1960b) Second Emerson effect in the Hill reaction of Chlorella cells with quinone as oxidant. Science 132:421

Govindjee, Cederstrand C, Rabinowitch E (1961) Existence of absorption bands at 730-740 and 750-760 millimicrons in algae of different divisions. Science 134:391-392

Govindjee, Owens OvH, Hoch G (1963) A mass spectroscopic study of the Emerson enhancement effect. Biochim Biophys Acta $75: 281-284$

Govindjee R, Govindjee, Hoch G (1964) Emerson enhancement effect in chloroplast reactions. Plant Physiol 39:10-14

Govindjee R, Rabinowitch EI, Govindjee (1968) Maximum quantum yield and action spectra of photosynthesis and fluorescence in Chlorella. Biochim Biophys Acta 162:530-544
Govindjee, Pulles MPJ, Govindjee R, Van Gorkom HJ, Duysens LNM (1976) Inhibition of the reoxidation of the secondary electron acceptor of Photosystem II by bicarbonate depletion. Biochim Biophys Acta 449:602-605

Govindjee, Amesz J, Fork DC (eds) (1986) Light emission by plants and bacteria. Academic Press, Orlando

Govindjee, Van de Ven M, Preston C, Seibert M, Gratton E (1990) Chlorophyll $a$ fluorescence lifetime distributions in open and closed Photosystem II reaction center preparations: analysis by multifrequency phase fluorometry. Biochim Biophys Acta 1015:173-179

Govindjee, Sestak Z, Peters WR (2002) The early history of "Photosyntetica", "Photosynthesis Research", and their publishers. Photosynthetica 40:1-11

Govindjee, Beatty JT, Gest H, Allen JF (eds) (2005) Discoveries in photosynthesis, Advances in photosynthesis and respiration, vol 20. Springer, Dordrecht

Govindjee, Kern JF, Messinger J, Whitmarsh J (2010) Photosystem II. Encyclopedia of life sciences (ELS). Wiley, Chichester. doi:10. 1002/9780470015902.a0000669.pub2, 15 pp; available on Govindjee's web site

Greenfield SR, Seibert M, Govindjee, Wasielewski MR (1997) Direct measurement of the effective rate constant for primary charge separation in isolated Photosystem II reaction centers. J Phys Chem 101:2251-2255

Harpaz I, Appelbaum W (1961) Accumulation of asparagine in maize plants infected by maize rough dwarf virus and its significance in plant virology. Nature 192:780-781

Hutchison RS, Xiong J, Sayre RT, Govindjee (1996) Construction and characterization of a Photosystem II D1 mutant (arginine-269glycine) of Chlamydomonas reinhardtii. Biochim Biophys Acta 1277:83-92

Jursinic P, Govindjee (1972) Thermoluminescence and temperature effects on delayed light emission (corrected for changes in quantum yield of fluorescence) in DCMU-treated algae. Photochem Photobiol 15:331-348

Jursinic P, Govindjee (1977a) The rise in chlorophyll $a$ fluorescence yield and decay in delayed light emission in tris-washed chloroplasts in the 6-100-microsecond time range after an excitation flash. Biochim Biophys Acta 461:253-267

Jursinic P, Govindjee (1977b) Temperature dependence of delayed light emission in the 6 to 340 microsecond range after a single flash in chloroplasts. Photochem Photobiol 26:617-628

Jursinic P, Govindjee, Wraight CA (1978) Membrane potential and microsecond to millisecond delayed light emission after a single excitation flash in in isolated chloroplasts. Photochem Photobiol 27:61-71

Kalaji HM, Goltsev V, Bosa K, Allakhverdiev SI, Strasser RJ, Govindjee (2012) Experimental in vivo measurements of light emission in plants: a perspective dedicated to David Walker. Photosynth Res 114:69-96

Kambara T, Govindjee (1985) Molecular mechanism of water oxidation in photosynthesis based on the functioning of manganese in two different environments. Proc Natl Acad Sci USA 82:6119-6123

Keränen M, Mulo P, Aro E-M, Govindjee, Tyystjärvi E (1998) Thermoluminescence $\mathrm{B}$ and $\mathrm{Q}$ bands are at the same temperature in an autotrophic and a heterotrophic D1 protein mutant of Synechocystis sp. PCC 6803. In: Garab G (ed) Photosynthesis: mechanisms and effects, vol II. Kluwer Academic Publishers (now Springer), Dordrecht.

Khanna, Wagner R, Junge W, Govindjee (1980) Effects of $\mathrm{CO}_{2-}$ depletion on proton uptake and release in thylakoid membranes. FEBS Lett 121:222-224

Kiang NY, Siefert J, Govindjee, Blankenship RE (2007a) Spectral signatures of photosynthesis. I. Review of earth organisms. Astrobiology 7:222-251 
Kiang NY, Segura A, Tinetti G, Govindjee, Blankenship RE, Cohen M, Siefert J, Crisp D, Meadows VS (2007b) Spectral signatures of photosynthesis. II. Coevolution with other stars and the atmosphere on extra-solarworlds. Astrobiology 7:252-274

Kramer DM, Roffey RA, Govindjee, Sayre RT (1994) The At thermoluminescence band from Chlamydomonas reinhardtii and the effects of mutagenesis of histidine residues on the donor side of Photosystem II D1 polypeptide. Biochim Biophys Acta 1185:228-237

Krey A, Govindjee (1964) Fluorescence changes in Porphyridium exposed to green light of different intensity: a new emission band at $693 \mathrm{~nm}$ and its significance to photosynthesis. Proc Natl Acad Sci USA 52:1568-1572

Laloraya MM, Govindjee (1955) Effect of tobacco leaf curl and tobacco mosaic virus on the amino acid and amide content of Nicotiana sp. Nature 175:907

Laloraya MM, Govindjee, Rajarao T (1955) A chromatographic study of the amino acids (and sugars) of healthy and diseased leaves of Acalypha indica. Curr Sci (India) 24:203

Laloraya MM, Govindjee, Varma R, Rajarao T (1956) Increased formation of asparagine in Carica-curl virus infected leaves. Experientia 12:58-59

Lavorel J (1975) Luminescence. In: Govindjee (ed) Bioenergetics of photosynthesis. Academic Press, New York, pp 223-317

Magyarosy AC, Buchanan BB, Schürmann P (1973) Effect of a systemic virus infection on chloroplast function and structure. Virology 55:426-438

Mar T, Govindjee (1971) Thermoluminescence in spinach chloroplasts and in Chlorella. Biochim Biophys Acta 226:200-203

Mar T, Govindjee (1972) Kinetic models of oxygen evolution in photosynthesis. J Theor Biol 36:427-446

Matsubara S, Chen Y-C, Caliandro R, Govindjee, Clegg RM (2011) Photosystem II fluorescence lifetime imaging in avocado leaves: contributions of the lutein-epoxide and violaxanthin cycles to fluorescence quenching. J Photochem Photobiol B 104:271-284

Merkelo H, Hartman SR, Mar T, Singhal GS, Govindjee (1969) Mode locked lasers: measurements of very fast radiative decay in fluorescent systems. Science 164:301-302

Mohanty P, Munday JC Jr, Govindjee (1970) Time-dependent quenching of chlorophyll $a$ fluorescence from (Pigment) system II by (Pigment) system I of photosynthesis in Chlorella. Biochim Biophys Acta 223:198-200

Mohanty P, Papageorgiou GC, Govindjee (1971) Fluorescence induction in the red alga Porphyridium cruentum. Photochem Photobiol 14:667-682

Moore G, Ananyev G, Govindjee (2012) Young research investigators honored at the 2012 Gordon Research Conference on photosynthesis. Photosynth Res 114:137-142

Mulo P, Tyystjärvi T, Tyystjärvi E, Govindjee, Maenpaa P, Aro E-M (1997) Mutagenesis of the D-E loop of Photosystem II reaction centre protein D1. Function and assembly of Photosystem II. Plant Mol Biol 33:1059-1071

Munday JC Jr, Govindjee (1969a) Light-induced changes in the fluorescence yield of chlorophyll $a$ in vivo. III. The dip and the peak in fluorescence transient of Chlorella pyrenoidosa. Biophys J 9:1-21

Munday JC Jr, Govindjee (1969b) Light-induced changes in the fluorescence yield of chlorophyll $a$ in vivo. IV. The effect of preillimination on the fluorescence transient of Chlorella pyrenoidosa. Biophys J 9:22-35

Najafpour MM, Moghaddam AN, Allakhverdiev SI, Govindjee (2012) Biological water oxidation: lessons from nature. Biochim Biophys Acta 1817:1110-1121

Nanba O, Satoh N (1987) Isolation of a Photosystem II reaction center consisting of D-1 and D-2 polypeptides and cytochrome $b-555$. Proc Natl Acad Sci USA 84:109-112
Nickelsen K, Govindjee (2011) The maximum quantum yield controversy: Otto Warburg and the "Midwest Gang". Bern studies in the history and philosophy of science, Bern, Switzerland

Orr L, Govindjee (2013) Photosynthesis web resources. Photosynth Res 115:179-214

Owens OH, Hoch G (1963) Enhancement and de-enhancement effect in Anacystis nidulans. Biochim Biophys Acta 75:183-186

Papageorgiou GC (2012a) Contributions of Govindjee, 1955-1969. In: Eaton-Rye JJ, Tripathy BC, Sharkey TD (eds) Photosynthesis: plastid biology, energy conversion and carbon assimilation, Advances in photosynthesis and respiration, vol 34. Springer, Dordrecht, pp 803-814

Papageorgiou GC (2012b) Foreword. In: Itoh S, Mohanty P, Guruprasad KN (eds) Photosynthesis: Overviews on recent progress and future perspectives. IK Publishers, New Delhi, pp vii- $\mathrm{x}$

Papageorgiou GC, Govindjee (1967) Changes in intensity and spectral distribution of fluorescence. Effect of light treatment on normal and DCMU-poisoned Anacystis nidulans. Biophys J $7: 375-390$

Papageorgiou GC, Govindjee (1968a) Light-induced changes in the fluorescence yield of chlorophyll $a$ in vivoI. Anacystis nidulans. Biophys J 8:1299-1315

Papageorgiou GC, Govindjee (1968b) Light-induced changes in the fluorescence yield of chlorophyll $a$ in vivo. II. Chlorella pyrenoidosa. Biophys J 8:1316-1328

Papageorgiou GC, Govindjee (eds) (2004) Chlorophyll $a$ fluorescence: a signature of photosynthesis. Advances in photosynthesis and respiration, vol 19. Springer, Dordrecht

Papageorgiou GC, Govindjee (2011) Photosystem II fluorescence: slow changes-scaling from the past. J Photochem Photobiol B 104:258-270

Portis AR Jr, Govindjee (2012) William L. Ogren was honored with a lifetime achievement award by the Rebeiz foundation for basic research. Photosynth Res 110:1-8

Rabinowitch E, Govindjee (1969) Photosynthesis. Wiley, New York

Rajarao R, Laloraya MM, Govindjee (1956) Absence of some free amino acids from the diseased leaves of Trichosanthes angiuna. Naturwissenschaften 43:301

Ranjan S, Govindjee, Laloraya MM (1955) Chromatographic studies on the amino acid metabolism of healthy and diseased leaves of Croton sparsiflorus Morong. Proc Natl Acad Sci India 21B:42-47

Roffey RA, Kramer DM, Govindjee, Sayre RT (1994) Lumenal side histidine mutations in the D1 protein of Photosystem II affect donor side electron transfer in Chlamydomonas reinhardtii. Biochim Biophys Acta 1185:257-270

Rose S, Minagawa J, Seufferheld M, Padden S, Svensson B, Kolling DRJ, Crofts AR, Govindjee (2008) D1-arginine mutants (R257E, $\mathrm{K}$ and $\mathrm{Q}$ ) of Chlamydomonas reinhardtii have a lowered $\mathrm{Q}_{\mathrm{B}}$ redox potential: analysis of thermoluminescence and fluorescence measurements. Photosynth Res 99:449-468

Rutherford W, Govindjee, Inoue Y (1984) Charge accumulation and photochemistry in leaves studied by thermoluminescence and delayed light emission. Proc Natl Acad Sci USA 81:1107-1111

Salin ML, Homann PH (1971) Changes of photorespiratory activity with leaf age. Plant Physiol 48:193-196

Seibert M, Picorel R, Rubin AB, Connolly JS (1988) Spectral, photophysical and stability properties of isolated Photosystem II reaction center. Plant Physiol 87:303-306

Shevela D, Eaton-Rye JJ, Shen J-R, Govindjee (2012) Photosystem II and unique role of bicarbonate: a historical perspective. Biochim Biophys Acta 1817:1134-1151

Shevela D, Pishchalinkov RY, Eichacker LA, Govindjee (2013a) Oxygenic photosynthesis in cyanobacteria. In: Srivastava AK, Rai AN, Neilan BA (eds) Stress biology of cyanobacteria: 
molecular mechanisms to cellular responses. CRC Publishers, Taylor \& Francis Group, Abingdon, pp 3-40

Shevela D, Bjorn LO, Govindjee (2013b) Oxygenic photosynthesis. In: Razeghifard R (ed) Natural and artificial photosynthesis: solar power as an energy source. Wiley, Hoboken, pp 13-63

Shinkarev VP, Xu C, Govindjee, Wraight CA (1997) Kinetics of the oxygen evolution step in plants determined from flash-induced chlorophyll $a$ fluorescence. Photosynth Res 51:43-49

Shopes RJ, Blubaugh D, Wraight CA, Govindjee (1989) Absence of a bicarbonate-depletion effect in electron transfer between quinones in chromatophores and reaction centers of Rhodobacter sphaeroides. Biochim Biophys Acta 974:114-118

Spalding MH, Critchley C, Govindjee, Ogren WL (1984) Influence of carbon dioxide concentration during growth on fluorescence induction characterestics of the green alga Chlamydomonas reinhardtii. Photosynth Res 5:169-176

Stacy WT, Mar T, Swenberg CE, Govindjee (1971) An analysis of a triplet exciton model for the delayed light in Chlorella. Photochem Photobiol 14:197-219

Stemler A, Babcock GT, Govindjee (1974) The effect of bicarbonate on photosynthetic oxygen evolution in flashing light in chloroplast fragments. Proc Natl Acad Sci USA 71:4679-4683

Stirbet A, Govindjee (2011) On the relation between the Kautsky effect (chlorophyll $a$ fluorescence induction) and Photosystem II: basics and applications of the OJIP transient. J Photochem Photobiol B 104:236-257

Stirbet A, Govindjee (2012) Chlorophyll $a$ fluorescence induction: a personal perspective of the thermal phase, the J-I-P rise. Photosynth Res 113:15-61

Stirbet A, Govindjee, Strasser BJ (1998) Chlorophyll $a$ fluorescence induction in higher plants: modelling and numerical simulation. J Theor Biol 193:131-151

Strasser RJ, Govindjee (1991) The Fo and the O-J-I-P fluorescence rise in higher plants and algae. In: Argyroudi-Akoyunoglou JH (ed) Regulation of chloroplast biogenesis. Plenum Press, New York, pp 423-426

Strasser RJ, Govindjee (1992) On the O-J-I-P fluorescence transient in leaves and D1 mutants of Chlamydomonas reinhardtii. In: Murata N (ed) Research in photosynthesis, vol II. Kluwer Academic Publishers, Dordrecht, pp 29-32

Strasser RJ, Srivastava A, Govindjee (1995) Polyphasic chlorophyll $a$ fluorescence transient in plants and cyanobacteria. Photochem Photobiol 61:32-42
Strehler B, Arnold WA (1951) Light production by green plants. J Gen Physiol 34:809-820

Tatake VG, Desai TS, Govindjee, Sane PV (1981) Energy storage states of photosynthetic membranes: activation energies and lifetimes of electrons in the trap states by thermoluminescence method. Photochem Photobiol 33:243-250

Umena Y, Kawakami K, Shen J-R, Kamiya N (2011) Crystal structure of oxygen-evolving Photosystem II at a resolution of $1.9 \AA$. Nature 473:55-60

Vass I, Govindjee (1996) Thermoluminescence from the photosynthetic apparatus. Photosynth Res 48:117-126

Wang X, Cao J, Maroti P, Stilz HU, Finkele U, Lauterwasse C, Zinth W, Oesterhelt D, Govindjee, Wraight CA (1992) Is bicarbonate in Photosystem II the equivalent of the glutamate ligand to the iron atom in bacterial reaction centers? Biochim Biophys Acta 1100:1-8

Wasielewski MR, Fenton JM, Govindjee (1987) The rate of formation of P700 [ $\left.{ }^{+}\right]-$Ao $\left[{ }^{-}\right]$in Photosystem I particles from spinach as measured by picosecond transient absorption spectroscopy. Photosynth Res 12:181-190

Wasielewski MR, Johnson DG, Seibert M, Govindjee (1989) Determination of the primary charge separation rate in isolated Photosystem II reaction centers with 500 femtosecond time resolution. Proc Natl Acad Sci USA 86:524-548

Wydrzynski T, Govindjee (1975) A new site of bicarbonate effect in Photosystem II of photosynthesis: evidence from chlorophyll fluorescence transients in spinach chloroplasts. Biochim Biophys Acta 387:403-408

Wydrzynski T, Zumbulyadis N, Schmidt PG, Gutowsky HS, Govindjee (1976) Proton relaxation and charge accumulation during oxygen evolution in photosynthesis. Proc Natl Acad Sci USA 73:1196-1198

Xiong J, Hutchison RS, Sayre RT, Govindjee (1997) Modification of the Photosystem II acceptor side function in a D1 mutant (arginine-269-glycine) of Chlamydomonas reinhardtii. Biochim Biophys Acta 1322:60-76

Zilinskas BA, Govindjee (1975) Silicomolybdate and silicotungstate mediated dichlorophenyldimethylurea-insensitive Photosystem II reaction: electron flow, chlorophyll $a$ fluorescence and delayed light emission. Biochim Biophys Acta 387:306-319 